\title{
Long-distance communication and signal amplification in systemic acquired resistance
}

\author{
Jyoti Shah ${ }^{1 *}$ and Jürgen Zeier ${ }^{2 *}$ \\ ${ }^{1}$ Department of Biological Sciences, University of North Texas, Denton, TX, USA \\ 2 Department of Biology, Heinrich-Heine-University, Düsseldorf, Germany
}

\author{
Edited by: \\ Saskia C. M. Van Wees, Utrecht \\ University, Netherlands \\ Reviewed by: \\ Keiko Yoshioka, University of \\ Toronto, Canada \\ Robin K. Cameron, McMaster \\ University, Canada \\ *Correspondence: \\ Jyoti Shah, Department of Biological \\ Sciences, University of North Texas, \\ Life Sciences Building-B, Room \\ \# 418, 1155 Union Circle \#305220, \\ Denton, TX 76203, USA. \\ e-mail: shah@unt.edu \\ Jürgen Zeier, Department of \\ Biology, Heinrich-Heine-University, \\ 40225 Düsseldorf, Germany. \\ e-mail: juergen.zeier@ \\ uni-duesseldorf.de
}

Systemic acquired resistance (SAR) is an inducible defense mechanism in plants that confers enhanced resistance against a variety of pathogens. SAR is activated in the uninfected systemic (distal) organs in response to a prior (primary) infection elsewhere in the plant. SAR is associated with the activation of salicylic acid (SA) signaling and the priming of defense responses for robust activation in response to subsequent infections. The activation of SAR requires communication by the primary infected tissues with the distal organs. The vasculature functions as a conduit for the translocation of factors that facilitate long-distance intra-plant communication. In recent years, several metabolites putatively involved in long-distance signaling have been identified. These include the methyl ester of SA (MeSA), the abietane diterpenoid dehydroabietinal (DA), the dicarboxylic acid azelaic acid (AzA), and a glycerol-3-phosphate (G3P)-dependent factor. Long-distance signaling by some of these metabolites also requires the lipid-transfer protein DIR1 (DEFECTIVE IN INDUCED RESISTANCE 1). The relative contribution of these factors in long-distance signaling is likely influenced by environmental conditions, for example light. In the systemic leaves, the AGD2-LIKE DEFENSE RESPONSE PROTEIN1 (ALD1)-dependent production of the lysine catabolite pipecolic acid (Pip), FLAVIN-DEPENDENT MONOOXYGENASE1 (FMO1) signaling, as well as SA synthesis and downstream signaling are required for the activation of SAR. This review summarizes the involvement and interaction between long-distance SAR signals and details the recently discovered role of Pip in defense amplification and priming that allows plants to acquire immunity at the systemic level. Recent advances in SA signaling and perception are also highlighted.

\section{Keywords: azelaic acid, dehydroabietinal, glycerol-3-phosphate, methyl salicylate, pipecolic acid, DIR1}

\section{INTRODUCTION}

Plants employ multiple layers of defense to combat pathogens. These defenses include a combination of preformed and inducible mechanisms (Jones and Dangl, 2006; Spoel and Dong, 2012). In the pathogen-inoculated tissues, recognition by the plant of molecular patterns that are conserved amongst groups of microbes results in the activation of PTI (PAMP-triggered immunity), which contributes to basal resistance that controls the extent of pathogen growth. By contrast to PTI, ETI (effectortriggered immunity), which is activated in response to plant recognition of race-specific effectors released by a pathogen, has a more pronounced impact on curtailing pathogen growth. Local infection by a pathogen can further result in immunization of the rest of the foliage against subsequent infections, a phenomenon that was reported as early as in the 1930s (Chester, 1933) and phrased "systemic acquired resistance (SAR)" by Ross (1966) (Figure 1). SAR confers enhanced resistance against a broadspectrum of foliar pathogens. The beneficial effect of SAR has also been suggested to extend to the roots (Gessler and Kuc, 1982; Tahiri-Alaoui et al., 1993). The protective effect of SAR can be transferred to the progeny (Luna et al., 2012) and can confer a fitness advantage under conditions of high disease pressure (Traw et al., 2007).

Resistance in foliar tissues can also be enhanced by mycorrhizal associations and colonization of the rhizosphere by biocontrol fungi (Liu et al., 2007; Shoresh et al., 2010). Similarly, root colonization by plant growth-promoting rhizobacteria also enhances disease resistance in the foliage, a phenomenon that has been termed "induced systemic resistance (ISR)" (van Loon, 2007). SAR and ISR engage different mechanisms and as a result have an additive effect on foliar disease resistance (van Wees et al., 2000). SAR results in a heightened state of preparedness in the uninfected organs against subsequent infections. Furthermore, these tissues are primed to turn on defenses faster and stronger when challenged by pathogen (Conrath, 2011). Long-distance communication by the primary pathogen-infected organ with rest of the pathogen-free foliage is critical for the activation of SAR. Experiments by Joseph Kuc and colleagues led to the suggestion that this long-distance communication requires an intact phloem. In a series of grafting studies, they showed that the SAR signal can be transmitted from the pathogen-inoculated rootstock to the pathogen-free graft (scion) (Jenns and Kuc, 1979; 


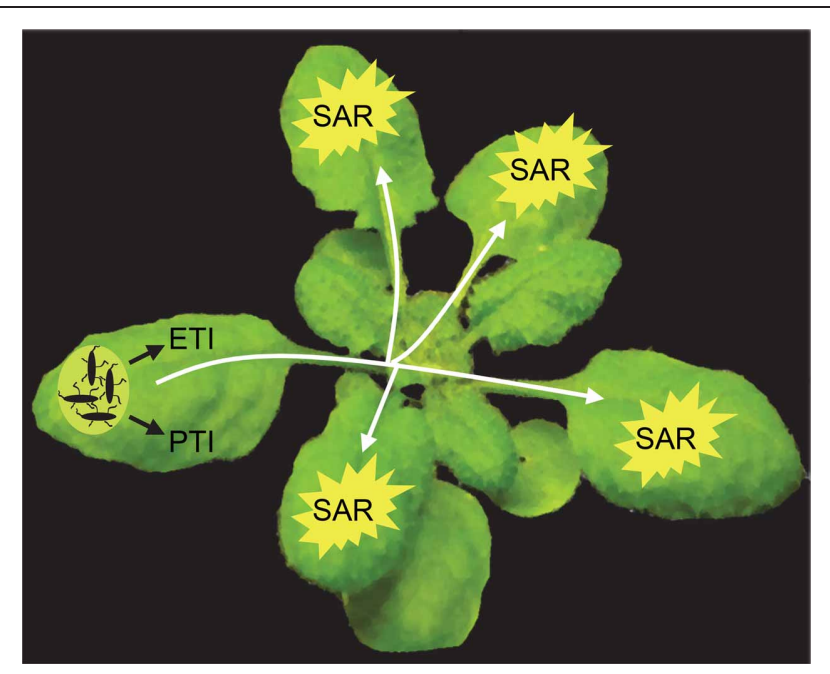

FIGURE 1 | Systemic acquired resistance. Pathogen infection results in the activation of defenses, for example PAMP-triggered immunity (PTI) and effector-triggered immunity (ETI), in the pathogen-infected organ. Simultaneously, the infected organ releases signals that are transported to rest of the foliage, where it induces systemic acquired resistance (SAR), which protects these organs against subsequent infections by a broad-spectrum of pathogens. The phloem is a likely conduit for the transport of these long-distance SAR signals. In the distal organs, effective signal amplification must take place to guarantee SAR establishment.

Tuzun and Kuc, 1985). Furthermore, long-distance transmission of the SAR signal in tobacco was disrupted when the phloem tissue in the stem above the pathogen-inoculated site was removed (Tuzun and Kuc, 1985). Similarly, girdling the petiole of the primary pathogen-inoculated leaf in cucumber (Cucumis sativus) prevented SAR from being activated in the distal leaves (Guedes et al., 1980). In Arabidopsis thaliana, the SAR-inducing activity can be recovered in the phloem sap-enriched petiole exudates (Pexs) obtained from leaves inoculated with a SAR-inducing pathogen (Maldonado et al., 2002; Chaturvedi et al., 2008; Jung et al., 2009), further suggesting that the phloem is a likely conduit for transmission of the long-distance SAR signal. It has been suggested, however, that the phloem may not be the exclusive conduit for transport of the long-distance SAR signal, since defenses were also induced in distal tissues that were not connected by the path of photoassimilate translocation from the primary-infected organ (Kiefer and Slusarenko, 2003). Pexs collected from pathogeninoculated leaves of Arabidopsis are effective in inducing SAR in tomato (Solanum lycopersicum), tobacco (Nicotiana tabacum), and wheat (Triticum aestivum) (Chaturvedi et al., 2008, 2012). Similarly, the SAR signal generated in the pathogen-inoculated cucumber rootstocks was found to confer protection on watermelon (Citrullus lanatus), and muskmelon (Cucumis melo) grafts (Jenns and Kuc, 1979), thus suggesting that the SAR signal is not genus- or species-specific.

\section{INVOLVEMENT OF SALICYLIC ACID SIGNALING IN SAR}

SAR is accompanied by an increase in levels of salicylic acid (SA) and its derivative SA-glucoside (SAG), and elevated expression of
SA-responsive genes in the pathogen-free organs. Elevated expression of the SA-responsive PR1 (PATHOGENESIS-RELATED 1) gene has routinely been used as a molecular marker of SAR. SA accumulation and signaling in these organs are primed to further increase to higher levels upon challenge with a pathogen (Jung et al., 2009; Návarová et al., 2012). Genetic studies in Arabidopsis and tobacco have confirmed that SA accumulation and signaling are critical for the disease resistance conferred by SAR. The Arabidopsis ics1 mutant, which is deficient in isochorismate synthase 1 activity that is required for SA synthesis, is SAR deficient (Wildermuth et al., 2001; Mishina and Zeier, 2007; Chaturvedi et al., 2008, 2012; Jung et al., 2009). Similarly, SAR is compromised in transgenic Arabidopsis and tobacco plants that express the SA degrading salicylate hydroxylase encoded by the Pseudomonas putida nahG gene (Vernooij et al., 1994; Lawton et al., 1995). In Arabidopsis, the FMO1 (FLAVIN-DEPENDENT MONOOXYGENASE1) gene is required for the systemic accumulation of SA that accompanies SAR (Mishina and Zeier, 2006; Chaturvedi et al., 2012). The role of FMO1 in SAR is discussed later in this review. The activation of SAR requires the NPR1 (NON-EXPRESSER OF PR GENES1) gene, which is an important regulator of SA signaling (Durrant and Dong, 2004; Chaturvedi and Shah, 2007). NPR1 is a transcription activator that is suggested to be one of the receptors for SA (Wu et al., 2012).

SA was found to accumulate at elevated levels in phloem sap collected from cucumber and tobacco leaves inoculated with SARinducing pathogens (Malamy et al., 1990; Métraux et al., 1990). Hence, till the early 1990s it was thought that SA is the likely longdistance signal in SAR. However, in 1994, Vernooij and coworkers provided genetic evidence arguing against a role for SA as the long-distance signal in SAR. They demonstrated that SAR was activated in wild-type tobacco scions that were grafted onto SAdeficient NahG rootstocks, which received the primary pathogen inoculation. In contrast, SAR was not activated in NahG scions grafted on wild-type rootstocks, thus confirming that although SA is required for the disease resistance conferred by SAR, SA per se is not the long-distance signal in SAR. These experiments also suggest that de novo synthesis of SA in the pathogen-free leaves is required for SAR. Studies with tobacco plants that were unable to accumulate SA due to epigenetic suppression of phenylalanine ammonia-lyase expression, also argued against a role for SA as the long-distance signal in SAR (Pallas et al., 1996).

\section{FACTORS INVOLVED IN LONG-DISTANCE SAR SIGNALING DIR1, A LIPID-TRANSFER PROTEIN, IS REQUIRED FOR LONG-DISTANCE SIGNALING IN SAR}

As noted above, the SAR inducing activity can be recovered in Pex collected from leaves inoculated with a SAR-inducing pathogen. The SAR inducing activity in Pex was sensitive to Proteinase K and Trypsin treatment (Chanda et al., 2011; Chaturvedi et al., 2012), thus suggesting the involvement of a protein(s) in the accumulation and/or systemic translocation of the SAR signal. The DIR1 (DEFECTIVE IN INDUCED RESISTANCE 1) protein, which exhibits structural similarities to the LTP2 family of lipid-transfer proteins, is a good candidate. DIR 1 is expressed in the phloem sieve elements and companion cells. Furthermore, DIR1 contains a signal peptide at its N-terminus that targets it 
for secretion to the cell surface (Champigny et al., 2011). Earlier, Maldonado et al. (2002) had identified dirl in a genetic screen for Arabidopsis mutants that were defective in SAR. Unlike the wildtype plant, localized inoculation with pathogen was unable to confer enhanced resistance in the distal leaves of the dirl mutant in response to challenge inoculation with a virulent pathogen. Although the dir1 mutant was responsive to the SAR signal present in Avr Pex collected from wild-type plants, similar exudates collected from dir1 when applied to wild-type plants were unable to enhance PR1 expression and disease resistance in the distal leaves (Maldonado et al., 2002; Chaturvedi et al., 2008). Thus, it was suggested that DIR1 is required for the accumulation and/or systemic movement of a SAR inducing factor. DIR1's function in defense seems to be specific to SAR since PTI was not compromised in the dir1 mutant (Maldonado et al., 2002). DIR1 homologs also have an important function in systemic enhancement of disease resistance in tobacco (Liu et al., 2011b). DIR1 contains two SH3 domains (Lascombe et al., 2008). Since, SH3 domains are known to facilitate interaction between proteins, these domains in DIR1 might facilitate interaction with other proteins.

\section{LONG-DISTANCE SIGNALING METABOLITES}

The last 5 years have seen the identification of plant-produced metabolites (Figure 2) that are enriched in Pex after pathogen infection and/or can be systemically transported, and are thus possibly involved in long-distance signaling in SAR (Shah, 2009; Dempsey and Klessig, 2012). These metabolites can be divided into two broad groups. The first group includes methyl salicylate (MeSA) and dehydroabietinal (DA), which when locally applied promote SA accumulation in the distal leaves (Park et al., 2007; Chaturvedi et al., 2012). The second group includes azelaic acid (AzA) and pipecolic acid (Pip) that are implicated in priming the faster and stronger accumulation of SA in response to pathogen infection (Jung et al., 2009; Návarová et al., 2012). A glycerol3-phosphate (G3P)-dependent factor has also been suggested to participate in SAR by facilitating the systemic translocation of DIR1 (Chanda et al., 2011). Evidence supporting the involvement of these molecules in long-distance communication and signal amplification in SAR is described below. Table 1 lists Arabidopsis genes/proteins involved in the synthesis and/or signaling by these metabolites.

\section{Methyl salicylate (MeSA)}

The volatile SA derivative MeSA (Figure 2), also known as the oil of winter-green, has previously been associated with plantinsect interaction and inter-plant communication (Shulaev et al., 1997; Van Poecke and Dicke, 2002; Snoeren et al., 2010). More recently, MeSA has been suggested to be involved in long-distance signaling in SAR (Dempsey and Klessig, 2012). MeSA levels were reported to increase in the Tobacco mosaic virus (TMV)-infected and the distal virus-free leaves of tobacco, as well as in the Pex collected from TMV-infected leaves (Park et al., 2007). TMV infection-induced SAR was attenuated in tobacco plants in which expression of the SAMT1 (SA-METHYLTRANSFERASE1) gene, which encodes a MeSA synthesizing S-adenosyl-L-methionine:<smiles>COC(=O)c1ccccc1O</smiles>

methyl salicylate

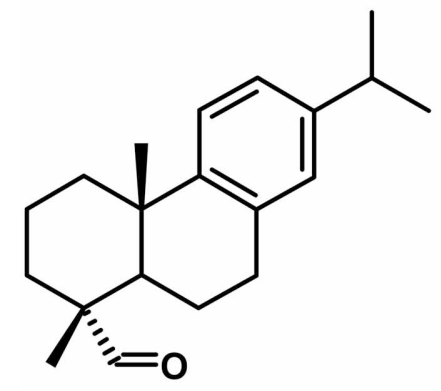

dehydroabietinal<smiles>O=C(O)c1ccccc1O</smiles>

salicylic acid<smiles>O=C(O)C1CCCCN1</smiles>

pipecolic acid<smiles>O=C(O)CCCCCCCC(=O)O</smiles><smiles>O=P(O)(O)OCC(O)CO</smiles>

glycerol-3-phosphate

FIGURE 2 | Plant synthesized metabolites suggested to function in long-distance transport and/or signal amplification during systemic acquired resistance. 
Table 1 | Arabidopsis genes involved in SAR.

\begin{tabular}{|c|c|c|}
\hline Gene & AtG\# & Function \\
\hline ALD1 & At2g13810 & Aminotransferase required for pipecolic acid biosynthesis \\
\hline$A Z 11$ & At4g12470 & Putative lipid-transfer protein \\
\hline CBP60g & At5g26920 & ACBP60 family transcription factor, involved in the control of ICS1 expression \\
\hline DIR1 & At5g48485 & Non-specific lipid-transfer protein \\
\hline MED15 & At1g15780 & Mediator subunit 15; transcriptional co-regulator \\
\hline MED16 & At4g04920 & Mediator subunit 16; transcriptional co-regulator \\
\hline MES9 & At4g37150 & MeSA esterase \\
\hline MPK3 & At3g45640 & MAP-kinase \\
\hline NPR1 & At1g64280 & SA receptor; transcriptional coactivator \\
\hline PHYB & At2g18790 & Red/far-red light perception; required for light's influence on SAR \\
\hline SARD1 & At1g73805 & ACBP60 family transcription factor, involved in the control of ICS1 expression \\
\hline SFD1 (GLY1) & At2g40690 & Dihydroxyacetone phosphate reductase; synthesizes glycerol-3-phosphate in plastids \\
\hline
\end{tabular}

salicylic acid carboxyl methyl-transferase, was silenced by RNAi (Park et al., 2007). Reciprocal grafting between SAMT1-silenced and wild-type tobacco plants indicated that SAMT1 was required in the primary TMV-infected leaves for the induction of SAR. The MeSA esterase encoded by the tobacco SABP2 (SA-BINDING PROTEIN 2) gene is also required for the activation of SAR in tobacco (Forouhar et al., 2005; Kumar et al., 2006; Park et al., 2007). A missense alteration $\left(\mathrm{Ser}_{81} \rightarrow \mathrm{Ala}_{81}\right)$ in SABP2 that resulted in loss of its MeSA esterase activity, also resulted in the inability to restore SAR in tobacco plants lacking endogenous SABP2 activity (Park et al., 2007). Furthermore, competitive inhibition of SABP2's esterase activity by 2,2,2,2'-tetrafluoroacetophenone, prevented the induction of SAR (Park et al., 2009). It has been suggested, as shown in Figure 3, that during the activation of SAR, SAMT1-synthesized MeSA is transported out of the pathogen-inoculated leaf to the distal leaves. In the distal leaves, MeSA is hydrolyzed by the esterase activity of SABP2 to produce SA, which along with de novo synthesized SA contributes to the activation of downstream signaling in the pathogen-free organs (Dempsey and Klessig, 2012).

MeSA was also shown to be required for the induction of SAR in potato (Solanum tuberosum) by arachidonic acid (Manosalva et al., 2010). MeSA levels increased in the arachidonic acid-treated and the distal untreated leaves of potato. Blocking MeSA accumulation by RNAi-mediated silencing of the SABP2 homologencoding METHYL ESTERASE 1 (StMES1) gene in potato compromised arachidonic acid-induced SAR. Furthermore, as in tobacco, 2,2,2,2'-tetrafluoroacetophenone prevented the induction of SAR in potato. 2,2,2,2'-tetrafluoroacetophenone also blocked SAR in Arabidopsis (Park et al., 2009). Knock-down of expression of multiple AtMES genes, which encode putative MeSA esterases in Arabidopsis, also attenuated SAR, however, only in $50 \%$ of experiments (Vlot et al., 2008; Chaturvedi et al., 2012).
Similarly, while Liu et al. (2010) observed that SAR was weaker in the Arabidopsis bsmt1 mutant, which lacks a MeSA synthesizing benzoic acid/salicylic acid methyl transferase 1, Attaran et al. (2009) noted that despite the MeSA deficiency, the bsmt1 mutant plants were SAR competent. These studies suggest that the role of MeSA in SAR in Arabidopsis is likely impacted by additional factors. Light has been suggested to be a factor that likely influences the importance of MeSA in SAR in Arabidopsis (Liu et al., 2011a). Liu et al. (2011a) noted that when the primary inoculation with the SAR inducing bacteria was conducted early during the light period, MeSA was less important for SAR. However, when the primary inoculation occurred close to the onset of the dark period, MeSA was comparatively more important for SAR.

In comparison to the wild-type plant, expression of the BSMT1 gene and MeSA content were higher in the pathogen-inoculated and the distal leaves of the dir1 mutant (Liu et al., 2011b). In contrast, the content of free SA and SAG were lower in dirl tissues. Liu et al. (2011b) have suggested that DIR1 depresses the conversion of SA to MeSA, resulting in SA accumulation in the systemic organs expressing SAR. A similar correlation between DIR1 and SAMT1 expression was observed in tobacco as well (Liu et al., 2011b).

\section{Dehydroabietinal (DA)}

Terpenoids form one of the largest families of secondary metabolites in plants (Tholl, 2006). The abietane family of diterpenoids, which are components of oleoresin produced by conifers, have pharmacological and industrial applications (Trapp and Croteau, 2001; Bohlmann and Keeling, 2008). These compounds are also produced by angiosperms (Hanson, 2009), but their function in plants is unclear. Chaturvedi et al. (2012) purified DA, an abietane type diterpenoid, as a SAR-inducing factor from Avr Pex. Deuterated DA when applied to Arabidopsis leaves was rapidly 


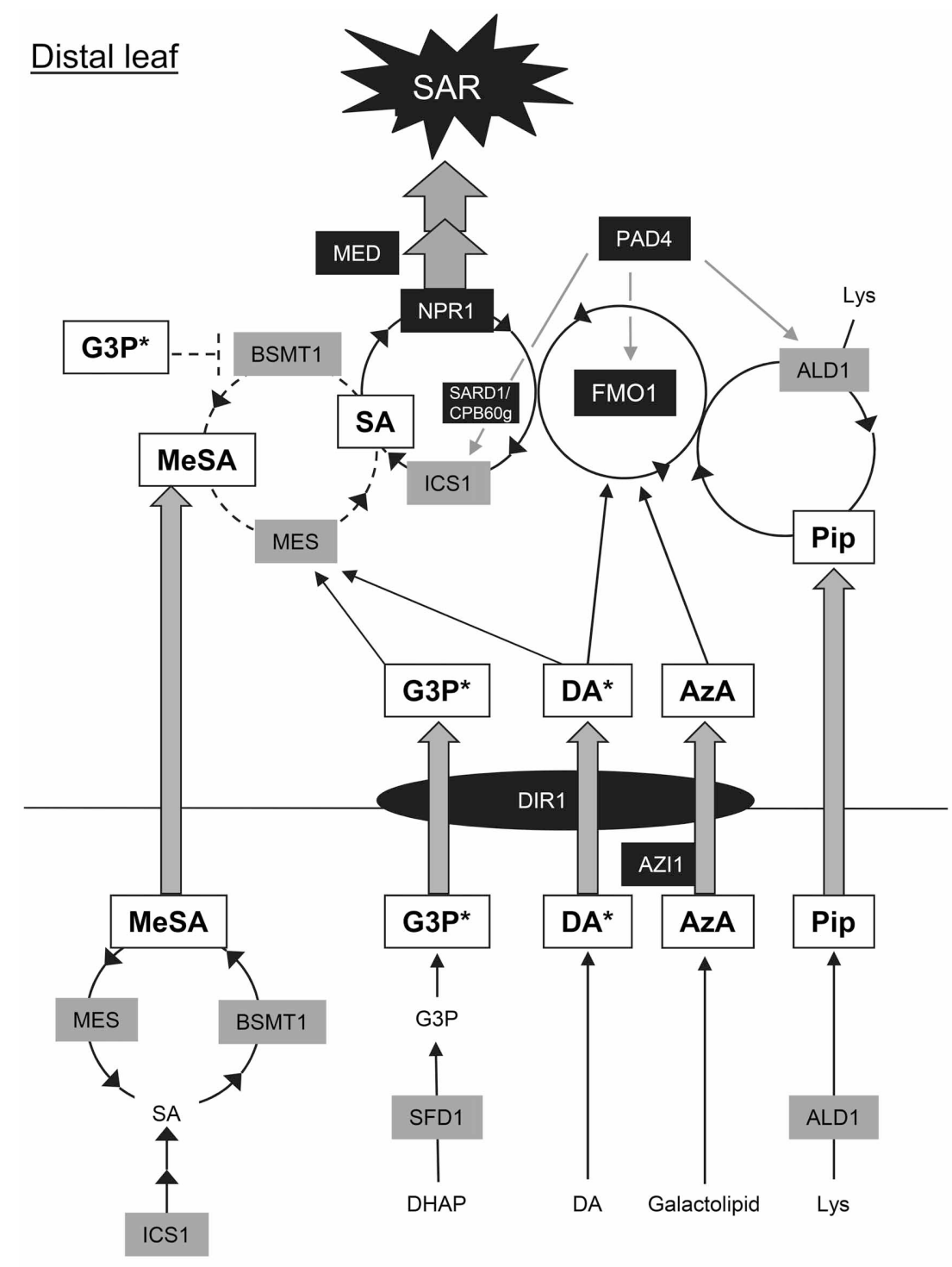

\section{Primary Pathogen-inoculated leaf}

FIGURE 3 | SAR circuitry involving a network of signaling molecules. Studies in Arabidopsis and to a lesser extent in tobacco have indicated that multiple signaling molecules participate in SAR and that the role of some of these signals is influenced by the environment. The genes listed in this model are from Arabidopsis. Events in the primary pathogen-infected leaf: In Arabidopsis, increased activity of ICS1, resulting from pathogen-induced expression of the corresponding gene, provokes increased SA accumulation. A fraction of the accumulating SA is converted to MeSA by BSMT1. In tobacco, the high level of SA was simultaneously shown to inhibit the MeSA esterase (MES) activity of SABP2, thus ensuring increase in MeSA level. Glycerol-3-phosphate (G3P), azelaic acid (AzA), and pipecolic acid (Pip) levels also increase in response to pathogen inoculation. SFD1 (GLY1) catalyzes the synthesis of glycerol-3-phosphate from dihydroxyacetone phosphate (DHAP). AzA has been suggested to be synthesized from galactolipids by a non-enzymatic method. Pip is synthesized from lysine (Lys) via the ALD1 aminotransferase and heavily accumulates in infected leaves. Expression of the ALD1 gene is induced in response to pathogen inoculation. Absolute levels of DA do not change. However, DA is mobilized from a non-signaling low-molecular weight to a high molecular weight signaling DA (DA*) complex in response to pathogen inoculation. Trypsin treatment destroys the high molecular weight $\mathrm{DA}^{*}$ complex, suggesting the presence of proteins in this complex. The AzA-inducible AZI1 gene is required for AzA-induced SAR and also promotes DA*-induced SAR. However, its involvement in SAR induced by the other factors is not known. DIR1, a putative non-specific lipid-transfer protein, is postulated to be involved in transport of a signal required for SAR. Genetic studies indicate that DIR1 is required for G3P, DA, and AzA-induced SAR. Events in the distal (systemic) leaf: Systemic transport of MeSA, a G3P-derived factor (G3P*), DA*, AzA, DIR1, and, possibly, Pip from the pathogen-inoculated leaf to the distal leaves occurs via the vasculature, most probably the phloem. G3P* and DIR1 have been suggested to facilitate long-distance transport of each other. DA* and G3P* promote accumulation of MES transcript (and likely the corresponding protein). Simultaneously, G3P* and DIR1 down-regulate expression of $B S M T 1$, thus ensuring that the equilibrium is in favor of conversion of MeSA to SA. An amplification loop involving ALD1, Pip, FMO1, ICS1, SA, and the SA receptor NPR1, promotes Pip and SA accumulation. PAD4 regulates the expression of ALD1, FMO1, SARD1, CPB60g, and ICS1.

(Continued) 


\section{FIGURE 3 | Continued}

NPR1 activation by SA leads to the expression of defense genes that contribute to SAR. MED transcriptional co-regulator subunits seem to act downstream of NPR1. Pip and FMO1 are required for the induction of ICS1 expression and accumulation of SA in the pathogen-free distal leaves. ICS1 expression is also controlled by SARD1 and CPB60g, a partly redundant pair of transcription factors. DA*, AzA and Pip signals converge at FMO1, which is required for activation of SAR by these signal molecules. It is likely that FMO1 is also required for G3P* and MeSA-induced SAR. However, this needs to be tested. ALD1 is a point of convergence of the AzA and Pip pathways. Pip acting through an amplification loop involving FMO1, promotes ALD1 expression and thus its own synthesis. DIR1 is essential for SAR induced by MeSA, G3P*, DA*, and AzA. Whether it is required for Pip-induced SAR is not known. DA is shown to interact synergistically with AzA and the SFD1-dependent mechanism. White and gray boxes represent the signaling molecules and biosynthetic enzymes, respectively. Signaling/transport proteins are represented by black boxes/ovals. Gray-filled arrows represent possible long-distance transport. Black arrows indicate positive regulation (induction), while black lines ending with a bar indicate negative regulation The solid line used for the Pip/SA amplification cycle symbolizes a robust requirement for this part of the circuit for SAR. The contributions of MeSA, DIR1, and G3P to SAR establishment seem less prominent when plants receive a prolonged period of light after pathogen contact. transported out of the leaf and recovered from the untreated leaves. DA is one of the most potent inducer of SAR that is active when applied as picomolar solutions to leaves of Arabidopsis, tobacco, and tomato (Chaturvedi et al., 2012). Local application of DA systemically induced SA accumulation and PR1 expression in the untreated leaves (Chaturvedi et al., 2012). DA induced SAR was attenuated in the SA deficient NahG transgenic and ics 1 ics 2 double mutant plants and in the SA signaling-deficient npr1 mutant, thus confirming that DA functions upstream of SA accumulation and signaling. The FMO1 gene, although not required for SA accumulation in the DA-treated leaves, was required for systemic SA accumulation in DA-treated plants and DA-induced SAR.

Unlike the other SAR signal molecules described here (Figure 2), DA content did not increase in the pathogeninoculated leaves and Pex during SAR. However, when Avr Pex collected from Avr pathogen-treated leaves was subjected to molecular sieve chromatography, DA was found to be enriched in the biologically active HMW fraction $(>100 \mathrm{kD}$ ) (Chaturvedi et al., 2012). By comparison, in Pex derived from mockinoculated leaves, DA was enriched in a LMW fraction $(<30 \mathrm{kD})$ that was unable to induce SAR. Chaturvedi et al. (2012) have proposed that the rate limiting step in SAR is the mobilization of DA from the biologically inactive LMW pool into a biologically active signaling form $\left(\mathrm{DA}^{*}\right)$ that is present in the HMW pool. Trypsin treatment, which destroys the SAR inducing activity of Avr Pex, also reduced DA content in HMW, suggesting that DA is associated with proteins in the HMW pool. What are the proteins in this HMW pool? Is DIR1 one of the proteins in this pool? Additional evidence with plants that are deficient in $\mathrm{DA}^{*}$ are also needed to determine if $\mathrm{DA}^{*}$ is essential for biologically-induced SAR.

\section{Azelaic acid (AzA)}

In tissues exhibiting SAR, SA accumulation is primed for faster and stronger induction in response to pathogen inoculation. Azelaic acid (AzA) (Figure 2), a nine carbon dicarboxylic acid has been suggested to be a factor involved in this priming response in Arabidopsis (Jung et al., 2009). AzA levels in Avr Pex collected from Arabidopsis leaves were found to be substantially higher than in Pex collected from mock-inoculated leaves. Local application of AzA systemically enhanced disease resistance. Deuterated AzA applied to Arabidopsis leaves was recovered in Pex and in the untreated leaves, suggesting that AzA is systemically translocated through the plant. AzA-mediated resistance required SA synthesis and signaling. However, unlike MeSA and DA, AzA application was not sufficient to promote SA accumulation and PR1 expression in Arabidopsis leaves. Instead, pathogen-induced SA accumulation and PR1 expression were faster and stronger in plants that were previously treated with AzA, suggesting that AzA is a priming factor. FMO1 and DIR1 were required for AzA-induced SAR. Also required for AzA induced SAR is ALD1, an aminotransferase that is involved in the synthesis of pipecolic acid (Pip), which as described below is involved in signal amplification during SAR (Návarová et al., 2012). The AZI1 (AZELAIC ACID-INDUCED 1) gene, which encodes a putative lipid-transfer protein, was transiently expressed at elevated levels in AzA-treated plants. Experiments with the azi1 mutant confirmed that $A Z I 1$ is required for AzAand biologically-induced SAR. The SAR associated priming of SA accumulation/signaling were attenuated in the azil mutant. Unlike Avr Pex from wild-type plants, local application of Avr Pex collected from the azil mutant was unable to systemically enhance disease resistance in wild-type plants. Furthermore, while locally applied Avr Pex and AzA were capable of enhancing disease resistance in the treated leaves of wild-type and azil mutant, they were unable to promote disease resistance in the distal leaves of the azil mutant compared to the wild-type plant. Thus, it has been suggested that $A Z I 1$ is required for the accumulation and/or translocation of a SAR signal (Jung et al., 2009).

A potential mechanism for the synthesis of AzA is by oxidation of 9-oxononanoic acid synthesized from fatty acids by the action of 9-lipoxygenase and hydroperoxide lyase. Indeed, mutation in the LOX1 gene, which encodes one of the two 9-lipoxygenase in Arabidopsis, disrupts SAR (Vicente et al., 2012). However, Avr pathogen inoculation-induced accumulation of AzA was retained in the lox1 lox5 double mutant (Zoeller et al., 2012). Zoeller et al. (2012) suggested that AzA is a general marker of lipid peroxidation that is synthesized by a free-radical based mechanism from galactolipids, rather than a general immune signal. Moreover, Návarová et al. (2012) showed that SAR can occur without the concomitant accumulation of AzA in Pex collected from virulent pathogen-treated plants. Zoeller et al. (2012) reported that AzA content in virulent pathogen-inoculated leaves was only slightly higher than in mock-inoculated leaves. This could explain the lack of AzA increase in Pex collected from virulent pathogen-inoculated leaves (Návarová et al., 2012), compared to that observed in Avr Pex (Jung et al., 2009). None-the-less, 
taken together these recent studies by Zoeller et al. (2012) and Návarová et al. (2012) suggest that systemic translocation of AzA is not essential for the establishment of SAR per se, but when it is translocated, AzA can add to the strength of systemic immunity observed during SAR.

\section{SFD1-synthesized glycerol-3-phosphate-derived factor and its interplay with DIR1}

sfd1 (suppressor of fatty acid desaturase deficiency 1) mutants were identified in a screen for suppressors of the constitutive SAR and dwarf phenotypes of the lipid metabolism ssi2 (suppressor of SA-insensitivity 2) mutant (Nandi et al., 2003, 2004), which itself was identified as a suppressor of the nprl mutant (Shah et al., 2001). sfd1 mutants had defects in lipid composition, in particular levels of the plastid-localized 34:6-MGDG (monogalactosyldiacylglycerol) were lower in the $s f d 1$ mutant, compared to the wild-type plant, while levels of 36:6-MGDG were higher in the $s f d 1$ mutant. Biologically-induced SAR was compromised in the sfd1 mutant (Nandi et al., 2004; Chaturvedi et al., 2008, 2012). The SAR defect of the $s f d 1$ mutant was characterized by the lack of systemic increase in SA content and PR1 transcript in response to localized pathogen inoculation. The $s f d 1$ mutant was responsive to SA (Nandi et al., 2004), and local application of Avr Pex from wild-type plants complemented the SAR defect of the sfd1 mutant (Chaturvedi et al., 2008), suggesting that the $s f d 1$ mutant is sensitive to the long-distance SAR signal. In contrast, Avr Pexs collected from the $s f d 1$ mutant were unable to induce SAR when applied to wild-type plants, indicating that the sfd 1 mutant is defective in the accumulation and/or translocation of a long-distance translocated SAR signal (Chaturvedi et al., 2008). DA content was not adversely impacted in the sfd 1 mutant. However, in agreement with a role for SFD1 in long-distance signaling leading to systemic SA accumulation, the sfdl mutant exhibited reduced sensitivity to the SAR-inducing activity of DA (Chaturvedi et al., 2012).

SFD1 encodes a plastid-localized dihydroxyacetone phosphate (DHAP) reductase that synthesizes glycerol-3-phosphate (G3P) (Figure 2) (Nandi et al., 2004), an important precursor in the synthesis of several biomolecules, including membrane and storage lipids. SFD1's DHAP reductase activity and its localization to the plastids were shown to be critical for its involvement in SAR, suggesting that SFD1 synthesized G3P, or a product thereof, is required for the accumulation and/or long-distance transport of a SAR signal (Lorenc-Kukula et al., 2012). More recently, Chanda et al. (2011) showed that SAR is also attenuated in the gly1 mutant, which contains a mutation in the SFD1 gene in Arabidopsis accession Columbia. However, unlike $s f d 1$, which is in the accession Nössen, the glylallele was not defective in the SAR associated systemic enhancement of SA accumulation and PR1 expression. In Arabidopsis, G3P levels were reported to be elevated in the pathogen-inoculated and the distal pathogen-free leaves, as well as Avr Pex (Chanda et al., 2011). Chanda et al. (2011) further showed that SAR could be restored in the gly1 mutant by co-applying G3P with Avr Pex, thus confirming an important role for G3P, or a G3P-derived factor in long-distance signaling associated with SAR. Since locally applied ${ }^{14} \mathrm{C}$-labeled G3P could not be recovered in the systemic leaves, G3P per se is unlikely to be the systemically translocated SAR signal. Rather, a G3P-dependent factor is likely involved in long-distance signaling. These results also suggest that the systemic increase in G3P observed in SAR likely results from de novo synthesis.

Although G3P, when co-applied with Pex, was capable of enhancing disease resistance in the distal leaves, G3P by itself was not sufficient to induce systemic resistance (Chanda et al., 2011). These results suggest that additional factors that are present in Pex are required for G3P to induce SAR. An earlier study had shown that Avr Pex from sfdl to dirl, although ineffective in inducing SAR when applied individually, when co-applied were effective inducers of systemic disease resistance (Chaturvedi et al., 2008). This cross-complementation experiment suggested that the SFD1- and DIR1-dependent factors might function together in long-distance signaling. Indeed, G3P when co-applied with DIR1 protein was capable of enhancing systemic disease resistance (Chanda et al., 2011). G3P levels were also lower in Avr Pex from dir1 mutant, leading to the suggestion that DIR1 and the G3P-dependent factor are required for systemic translocation of each other. Whether G3P or a G3P-dependent factor binds DIR1 is not known. G3P applied with Pex up-regulates MES9 expression and simultaneously down-regulates BSMT1 expression in the distal un-treated leaves (Chanda et al., 2011). As mentioned earlier, MES9 is a putative MeSA esterase, while BSMT1 is involved in MeSA synthesis. However, G3P application did not result in systemic increase in SA and SAG content (Chanda et al., 2011). Hence, the altered MES9 and BSMT1 expression may not be important for G3P-induced SAR, or alternatively their importance might be dictated by other factors. Liu et al. (2011b) showed that similar to its impact on the contribution of MeSA in SAR, light influenced the contribution of the G3P-dependent factor in SAR. The gly 1 mutant was SAR competent when the primary inoculation with the SAR-inducing microbe was conducted early during the light period. However, when the primary inoculation occurred close to the onset of the dark period, the gly 1 mutant was SAR-defective.

\section{SAR SIGNALING AND SIGNAL AMPLIFICATION IN SYSTEMIC LEAVES}

Long-distance signals generated and released from the primary pathogen-inoculated leaves are supposed to be perceived by the cells in the distal organs for SAR initiation at the whole plant level (Figure 1). The receptors of individual mobile signals which activate SAR signaling in the distal organs are yet to be identified. Early signaling events result in the systemic accumulation of SA, and subsequent increases in expression of a battery of defense-related genes (SAR genes) is thought to contribute to the enhanced state of broad-spectrum resistance (Sticher et al., 1997). Compared to PTI and ETI, local forms of induced resistance that are activated upon direct pathogen contact via recognition of microbial elicitors (Jones and Dangl, 2006), induction of systemic immunity is indirectly triggered by mobile, endogenous plant signals. The overall direct defense eliciting capacity of numerous PAMPs and/or pathogen released effectors at inoculation sites is probably higher than the elicitor strength of endogenous long-distance signals in distal leaves. It has been suggested that amplification of the stimulus delivered by the SAR signals 
is important for SAR establishment (Mishina and Zeier, 2006). Recent findings provide evidence that pipecolic acid (Pip), a common lysine catabolite in plants and animals, acts as a central component of a feedback amplification mechanism that is critical for systemic SA accumulation and SAR (Návarová et al., 2012).

\section{PIPECOLIC ACID—A CRITICAL SAR SIGNAL THAT ORCHESTRATES DEFENSE AMPLIFICATION \\ Pipecolic acid systemically accumulates in pathogen-inoculated plants}

The cyclic non-protein amino acid L-Pip (homoproline; Figure 2) is present in plants throughout the plant kingdom (Morrison, 1953). L-Pip is a common catabolite of L-Lys in plants and animals (Broquist, 1991), and the pipecolate pathway represents the main degradation pathway of Lys in mammalian brains (Chang, 1976). In plants, Pip levels increase following chemical treatments that affect growth and upon osmotic stress (Yatsu and Boynton, 1959; Moulin et al., 2006). Pálfi and Dézsi (1968) reported that Pip accumulates both in virus-infected potato and tobacco and in fungus-infected rice leaves. They therefore described Pip as an indicator of abnormal protein metabolism in diseased plants. Since then, the physiological function of Pip in plants has remained elusive, albeit it was found to exert flowerinducing activity in the aquatic plant Lemna gibba (Fujioka et al., 1987).

Pip strongly accumulates, alongside with several other free amino acids, its precursor Lys, and another Lys catabolite, $\alpha$-aminoadipic acid (Aad), in Arabidopsis leaves inoculated with SAR-inducing (virulent or Avr) P. syringae and in leaves treated with bacterial PAMPs (Návarová et al., 2012). Moreover, the only amino acid found to substantially increase in leaves distal from sites of pathogen inoculation in this study was Pip. Pip and SA therefore share the characteristic of systemically accumulating in plants upon localized pathogen inoculation. A time-resolved analysis in SAR-induced Arabidopsis indicates that systemic Pip levels start to significantly rise before marked elevations of SA are detectable in the systemic tissue (Návarová et al., 2012).

Pip biosynthesis and accumulation proceeds via ALD1, because the ald 1 mutant completely lacks local and systemic accumulation of Pip upon Avr or virulent P. syringae-inoculation (Návarová et al., 2012). ALD1 transcript levels rise both locally and systemically in pathogen-inoculated Arabidopsis (Song et al., 2004a). In vitro, recombinant ALD1 has aminotransferase activity with strong substrate preference for Lys (Song et al., $2004 b)$. It is conceivable that $\varepsilon$-amino- $\alpha$-ketocaproic acid and $\Delta$ 1-piperideine-2-carboxylic acid are direct reaction products of an ALD1-catalysed Lys aminotransferase reaction. However, the exact biochemistry of ALD1-mediated Pip production and the existence of a yet to postulate reductase that converts Lys transamination products to Pip remains to be clarified (Návarová et al., 2012).

\section{The Pip resistance pathway is central for SAR}

Pipecolate-deficient ald 1 plants fail to accumulate SA in distal leaf tissue following pathogen-inoculation and are fully compromised in SAR (Song et al., 2004a; Jing et al., 2011; Návarová et al., 2012).
However, ald1 plants regain the ability for systemic SA accumulation and SAR establishment when Pip is exogenously applied to the whole plant prior to pathogen treatment, demonstrating that Pip accumulation is critical for systemic SA production and SAR (Návarová et al., 2012). The ald1 mutant also exhibits attenuated local resistance to compatible and incompatible $P$. syringae, and this is accompanied with reduced local defense responses such as SA biosynthesis, camalexin accumulation, and defenserelated gene expression (Song et al., 2004a,b; Návarová et al., 2012). Exogenously applied Pip fully overrides the defects of ald 1 in PTI and ETI and increases the resistance of wild-type plants to bacterial infection. Moreover, Pip feeding of plants prior to inoculation boosts pathogen-triggered induction of SA biosynthesis, camalexin accumulation, and defense-related gene expression in wild-type and ald 1 plants, indicating that Pip strongly amplifies pathogen-triggered defense responses. The positive regulatory role of Pip on SA biosynthesis is particularly important for SA accumulation in distal leaves. It has been suggested that the early systemic increase of Pip at the onset of SAR functions as an initial trigger for signal amplification leading to the systemic increase in SA (Návarová et al., 2012).

Concomitant with SAR, localized $P$. syringae inoculation triggers enhanced expression of several hundred genes in the distal leaves of Arabidopsis wild-type plants. This massive switch in gene expression at the systemic plant level is totally lost in the fmo1 mutant (Mishina and Zeier, 2006). The flavin-dependent monooxygenase FMO1 was previously identified as a critical regulator of SAR and found necessary for effective local resistance to several bacterial and oomycete pathogens (Bartsch et al., 2006; Koch et al., 2006; Mishina and Zeier, 2006; Jing et al., 2011). Like ALD1, FMO1 is necessary for the systemic accumulation of SA upon SAR induction (Mishina and Zeier, 2006). In contrast to ald1, however, fmo1 fails to establish Pip-induced resistance to bacterial infection. These data indicate that FMO1 functions downstream of Pip and upstream of SA in SAR (Návarová et al., 2012). Importantly, Pip enhances both its own biosynthesis and downstream signaling in SAR via amplification of pathogentriggered ALD1 and FMO1 expression, indicating the existence of a positive feedback amplification loop with Pip as a central player (Figure 3; Návarová et al., 2012).

Biochemically characterized flavin-dependent monooxygenases from plants, animals, or fungi oxidize either $\mathrm{N}$ - or S-containing functional groups within small metabolic substrates. In Arabidopsis, FMOs of the YUCCA subgroup are capable of converting tryptamine to N-hydroxyl-tryptamine (Zhao et al., 2001), whereas members of the S-oxygenation subgroup $\left(\mathrm{FMO}_{\mathrm{GS}-\mathrm{OX}}\right)$ oxidize the sulfide group of Met-derived methylthioalkyl glucosinolates to sulfoxide moieties, thereby generating methylsulfinylalkyl glucosinolates (Li et al., 2008). A third subgroup consists of FMO1 and a pseudogene (Olszak et al., 2006; Schlaich, 2007). Interestingly, besides the inability of fmo1 to mediate Pip-induced resistance, fmol over-accumulates Pip in the pathogen-inoculated tissue during the later stages of infection. These observations are consistent with the hypothesis that FMO1 could be involved in the oxidation of Pip or a Pip derivative in the Pip signal amplification pathway (Návarová et al., 2012). 
Besides FMO1, PHYTOALEXIN-DEFICIENT4 (PAD4) and NPR1 constitute two other necessary components of both SAR and Pip-mediated resistance (Mishina and Zeier, 2006; Jing et al., 2011; Návarová et al., 2012). The lipase-like protein PAD4 is a positive regulator of SA biosynthesis and downstream signaling in plant defense (Zhou et al., 1998; Jirage et al., 1999). A similar double regulatory role exists for PAD4 also in the Pip pathway, since PAD4 not only promotes pathogen-induced Pip production but is also required for resistance promoted by Pip application (Návarová et al., 2012). PAD4 seems to exert its central defense regulatory role via transcriptional control of Pip- and SApathway genes, including ALD1, FMO1, and ICS1 (Figure 3; Song et al., 2004a; Bartsch et al., 2006; https://www.genevestigator. com).

How do the Pip and SA defense regulatory pathways relate to each other? The ics 1 mutant accumulates Pip in a wild-typelike manner in P. syringae-inoculated leaves, and exogenous Pip is able to significantly increase basal resistance to $P$. syringae in $i c s 1$, albeit not to the same extent as in the wild-type. These findings indicate that in the pathogen-inoculated leaves, Pip increases occur independently of ICS1-dependent SA biosynthesis, and suggest a partial competence for Pip to induce resistance in an SA-independent manner. By contrast, Pip-induced resistance is minimal in the nprl mutant. Thus, a function of NPR1 in Pip signal transduction that is unrelated to its well-described SA downstream regulatory function was proposed (Návarová et al., 2012).

These partly independent traits of the Pip and SA resistance pathways diminish when the distal rather than the locally infected tissue is considered. In the distal leaves of plants that were inoculated with pathogen on other leaves, SA content increase was fully dependent on $A L D 1$ and hence functional Pip biosynthesis, and downstream signaling involving FMO1 (Song et al., 2004a; Mishina and Zeier, 2006; Návarová et al., 2012). Conversely, systemic Pip accumulation strongly relies on FMO1 and ICS1mediated SA biosynthesis (Návarová et al., 2012). This reflects the afore-mentioned strong subjection of SAR establishment on effective signal amplification involving feedback mechanisms that integrate both Pip and SA signaling (Figure 3).

Above-described findings implicate a central role for the Pip resistance pathway for SAR. This is corroborated by a recent high throughput forward genetic screen for SAR-deficient Arabidopsis mutants (Jing et al., 2011). Amongst the 16 independent SARdefective mutants identified were six fmol, four ald 1 , and one pad4 alleles, as well as three ics 1 alleles. SAR is influenced by the availability of light and depends on intact phytochrome signaling (Zeier et al., 2004; Griebel and Zeier, 2008). A more recent study suggests that the duration of light exposure after bacterial infection influences the importance of individual signals for SAR. For instance, Arabidopsis dirl, glyl, and bsmt1 mutants proved SAR-defective when the SAR-inducing inoculation occurred late during the daylight period but were SAR-competent when the primary inoculation was performed early during the daylight period (Liu et al., 2011a). This suggests that the contributions of DIR1, G3P, and MeSA to SAR establishment are less prominent when plants receive a prolonged period of light after pathogen contact. The same study indicates that FMO1 is necessary for systemic resistance induction irrespective of the light regime applied (Liu et al., 2011a), suggesting that the FMO1 pathway is a point of convergence of various SAR signals, and a critical component for SAR under varying environmental conditions (Figure 3).

\section{Is Pip a SAR long-distance signal?}

In P. syringae-inoculated leaves, Pip production occurs along with the accumulation of several other pathogen-inducible metabolites (Griebel and Zeier, 2010; Ward et al., 2010; Chanda et al., 2011; Návarová et al., 2012). In distal leaves, a more specific response occurs and the increases in a relatively small number of metabolites, including SA, SA-glucoside (SAG), and Pip occurs (Návarová et al., 2012). Návarová et al. (2012) have performed a detailed comparative analysis of the composition of Pex collected from mock-treated and virulent $P$. syringae pv maculicola (Psm)-inoculated leaves between 6 and $48 \mathrm{~h}$, a time window during which the SAR long-distance information is transduced from the pathogen-inoculated to the distal leaves in their experimental system (Mishina et al., 2008). The applied methods allowed the detection and quantification of 30 defense-related metabolites and amino acids in Pex, including free SA, SAG, MeSA, AzA, JA, camalexin, and Pip. Strikingly, the only substance that exhibited a substantial (7-fold) increase in Pex from Psm-inoculated compared to Pex from mock-treated leaves was Pip. SA, AzA, JA, and camalexin, were not enriched in Pex collected from Psminoculated leaves, and Phenylalanine, SAG and MeSA showed only a small, 1.5- to 2-fold increase. Notably, many substances that strongly accumulated in Psm-inoculated leaves during the sampling period were not enriched in the respective Pex.

This selective and marked enrichment of Pip in Pex collected from Psm-inoculated leaves during SAR induction is consistent with the hypothesis of a Pip-specific transport out of inoculated leaves and, possibly, translocation of Pip to systemic leaves Návarová et al. (2012). Thus, a scenario is feasible in which Pip, after massive local accumulation, is transported from inoculated to distal leaves, leading to initial, moderate rises in systemic Pip levels (Figure 3). Consistent with this hypothesis, Návarová et al. (2012) detected small but significant pathogen-induced rises in distal leaves of fmol which are supposed to result from transport rather than de novo synthesis, because fmo1 lacks systemic up-regulation of the Pip biosynthesis gene ALD1. These modest systemic rises in Pip originating from transport could then drive further Pip production in the wild-type via up-regulation of ALD1 and subsequent FMO1-mediated activation of the Pip amplification cycle, and augmented Pip in systemic leaves would then potentiate the action of other SAR long-distance signals to fully realize SAR (Figure 3). However, further experimental evidence is needed to substantiate the hypothetical function of Pip as a long-distance signal. As a water-soluble amino acid, Pip would have ideal physicochemical properties to travel via the phloem.

\section{REGULATORY ASPECTS OF THE SA PATHWAY Regulation of ICS1 expression and SA accumulation during SAR}

In Arabidopsis and Nicotiana benthamiana, stress- and pathogeninduced SA biosynthesis proceeds via isochorismate synthase (Nawrath and Métraux, 1999; Wildermuth et al., 2001; Catinot et al., 2008). Accumulation of SA in distal leaves of locally 
inoculated Arabidopsis requires increased systemic expression of ISOCHORISMATE SYNTHASE1 (ICS1; Attaran et al., 2009). Recent studies have provided new insight into the regulation of ICS1 transcription. Zhang et al. (2010) identified two members of the plant-specific transcription factor family ACBP60, SAR-DEFICIENT1 (SARD1) and CALMODULINBINDING PROTEIN60G (CBP60g) as SAR-relevant Arabidopsis genes. Both genes are locally and systemically up-regulated upon P. syringae-inoculation, and the single loss-of-function sard 1 and cbpg60g mutants exhibited attenuated SAR. SAR and SA accumulation in both local and systemic leaves are completely lost in a sard 1 cbpg60g double mutant. Electrophoretic mobility shift analyses indicated that both SARD1 and CBPG60g bind to the ICS1 promoter in a sequence-specific manner (Zhang et al., 2010). The function of CBP60g but not SARD1 is dependent on calmodulin binding, and the expression of both genes is regulated by PAD4. Moreover, expression profiling indicates that CBP60g and SARD1 affect defense responses other than SA biosynthesis, and suggests a more significant role for CBG60g and SARD1 during earlier and later stages of defense activation, respectively (Wang et al., 2011). Thus, pathogen-induced ICS1 transcription is activated by a pair of partly redundant DNA binding proteins with different regulatory and temporal properties (Zhang et al., 2010; Wang et al., 2011).

\section{Perception of SA and NPR1 regulation}

Accumulating SA is sufficient to induce a subset of SA-responsive SAR genes such as the classical marker PR1 (Sticher et al., 1997). The transcriptional co-activator NPR1 is essential for SAR and is required for the predominant part of SA downstream responses, including activation of defense gene expression (Durrant and Dong, 2004). NPR1 target genes include PR1 and a number of genes involved in protein folding and secretion, implicating a critical role of the protein secretory pathway for SAR (Wang et al., 2005). T-DNA insertions in a subset of those genes, LUMINAL BINDING PROTEIN (BIP2), DEFENDER AGAINST APOPTOTIC DEATH1 (DAD1), and SEC61 $\alpha$, reduced secretion of the PR1 protein into the apoplast and the ability of the mutant plants to enhance disease resistance in response to S-methyl-1,2,3-benzothiadiazole-7-carbothioate (BTH), a chemical that triggers a SAR-like response (Wang et al., 2005). NPR1 can reside both in the nucleus and the cytosol, and nuclear localization is required to activate $P R 1$ transcription (Kinkema et al., 2000). In the cytosol, disulfide bridge-connected NPR1 oligomers are converted to monomers after treatment with chemical SAR inducers. SAR induction by chemical treatment or bacterial inoculation is thought to produce a reductive redox potential in the cytosol, and in vitro analyses indicate that similar redox changes are sufficient to trigger NPR1 oligomer to monomer transition, presumably by reduction of disulfide bonds. Moreover, NPR1 monomer transition is associated with its nuclear localization. Thus, a model was suggested in which SA accumulation during SAR provokes redox changes driving the transition from the inactive, cytosolic NPR1 oligomer to the active, nucleusresident NPR1 monomer (Mou et al., 2003). In addition to NPR1 oligomer/monomer transitions, other mechanisms might control the subcellular localization of NPR1. Li et al. (2012) have suggested that in tobacco, the WD40 domain containing protein TRANPARENT TESTA GLABRA2 sequesters NPR1 from the nucleus and thus represses SA/NPR1-mediated defense responses.

Yeast-two-hybrid assays suggest that, in the nucleus, Arabidopsis NPR1 can interact with TGA2, TGA5, and TGA6, three closely related members of the TGA2 subclade of bZIP transcription factors that control PR1 expression. The triple knockout mutant tga 2 tga5 tga6 is not able to establish SAR, but also exhibits about 50-fold higher basal PR1 expression than the wild-type, suggesting that TGA factors suppress PR1 transcription, in addition to promoting its induction in response to SA (Zhang et al., 2003). Indeed, the PR1 promoter contains negative regulatory elements that can be bound by TGA2, in association with NPR1, thereby controlling the inappropriate activation of PR1 in the absence of stress (Despres et al., 2000; Zhang et al., 2003; Kesarwani et al., 2007). Consistently, in vivo transcription assays by Rochon et al. (2006) demonstrated that TGA2 functions as a transcriptional repressor under basal conditions. In conditions of elevated SA, TGA2 is incorporated into a transactivating complex with NPR1 that stimulates PR1 transcription. An N-terminal BTB/POZ domain of NPR1 interacts with and negates the function of the TGA repressor (Boyle et al., 2009). Moreover, a C-terminal transacting domain of NPR1 that contains two critical cysteines ( $\mathrm{Cys}^{521}$ and $\mathrm{Cys}^{529}$ ) in an oxidized form is necessary for the activation of $P R 1$ transcription (Rochon et al., 2006).

Since SA was attributed a key regulatory function in inducible plant immunity and SAR (Malamy et al., 1990; Métraux et al., 1990), a bona fide SA receptor required for SA-induced defense gene activation has remained elusive. Interestingly, when expressed in yeast, tobacco NPR1 is sensitive to SA and activates the expression of genes in a stimulus-dependent manner (Maier et al., 2011). Recently, Wu et al. (2012) have identified NPR1 as a direct SA receptor, unraveling that SA perception and subsequent transcriptional activation of defense genes are contiguous events. Using equilibrium dialysis, they determined that ${ }^{14} \mathrm{C}$-labeled SA can bind to NPR1 protein with a dissociation constant comparable to those of other plant-hormone receptor-ligand interactions. Competitive binding experiments suggested that NPR1 interacts with the defense activators SA and BTH with higher affinities than with structurally related but inactive compounds such as MeSA, 4-hydroxybenzoic acid and catechol. Further, NPR1 can coordinately bind transition metals via $\mathrm{Cys}^{521}$ and $\mathrm{Cys}^{529}$, and inductively coupled plasma-mass spectrometry analyses indicated that the protein is preferentially associated with copper. Wu et al. (2012) established that SA is bound to NPR1 via the NPR1-linked copper, presumably by the coordination of the oxygen atoms of the free carboxylate group and the phenolic hydroxyl group in ortho position of its aromatic ring. Further, SA binding to NPR1 causes a conformational change in the C-terminal transactivation domain that favors NPR1 oligomer disassembly and liberates the transactivation domain from an inhibitory interaction with the $\mathrm{N}$-terminal $\mathrm{BTB} / \mathrm{POZ}$ domain, thereby promoting nuclear localization and activation of transcription, respectively (Wu et al., 2012). According to Wu et al. (2012), SA binding, but not reducing conditions (Mou et al., 2003), induces NPR1 oligomer disassembly. 
The BTB domain present in the N-terminus of NPR1 is generally found in proteins that interact with Cullin 3 (CUL3) ubiquitin E3 ligase which targets specific protein substrates for degradation by the proteasome. Cell-free degradation assays indicate that NPR1 is subject to protease-mediated degradation resulting in a continuous removal of NPR1 from the nucleus (Spoel et al., 2009). This abolishes the NPR1 coactivator activity and attenuates basal defense gene expression to prevent untimely activation of SAR. Moreover, SA treatment also promotes phosphorylation of NPR1, and thus facilitates ubiquitinylation by CUL3 ubiquitin E3 ligase and NPR1 degradation (Spoel et al., 2009). Spoel et al. (2009) further showed that this phosphorylation-mediated NPR1 turnover is necessary for SAR. Their model proposes that disposal of "exhausted" phosphorylated NPR1 from the target gene promoter allows "fresh" NPR1 to reinitiate the transcription cycle, thus allowing maximum $P R$ gene transcription during SAR.

Like NPR1, its paralogues NPR3 and NPR4 contain a BTB and an ankyrin repeat protein-protein interaction domain, which are characteristic for CUL3 substrate adaptors. Fu et al. (2012) observed that npr3 npr4 mutant plants, unlike the wild-type, lacked SA-induced NPR1 degradation, and in vitro pull down and co-immunoprecipitation assays indicated that both NPR3 and NPR4 interact with CUL3 ubiquitin ligase. Moreover, a yeast-twohybrid assay established that NPR1 can interact with both NPR3 and NPR4, whereby SA promotes the NPR1-NPR3 and disrupts the NPR1-NPR4 interaction. Fu et al. (2012) also demonstrated direct binding of $\left[{ }^{3} \mathrm{H}\right]$-labeled SA to NPR3 and NPR4, identifying NPR3 as a low affinity and NPR4 as a high affinity receptor for SA. In contrast to the findings of Wu et al. (2012), binding assays employed by Fu et al. (2012) did not detect a considerable binding affinity of SA to NPR1. In summary, the results of Fu et al. (2012) suggest that NPR3 and NPR4 function as adaptors of CUL3 ubiquitin E3 ligase and control NPR1 stability in an SA-dependent manner. This control mechanism seems to be required for ETI and SAR, because the npr3 npr4 double mutant exhibited attenuated ETI and reduced HR. Fu et al. (2012) also observed that systemic resistance could not be enhanced further by prior exposure to an Avr strain of P. syringae in the npr3 npr4 mutant. Hence, they concluded that the npr3 npr4 double mutant is SAR-defective. However, results presented in Fu et al. (2012) also show that PTI associated basal resistance was significantly higher in the npr3 npr4 double mutant than in wild-type plants. In fact, basal resistance in the npr3 npr4 double mutant was higher than the heightened resistance observed in SAR expressing wild-type plants (Fu et al., 2012). Thus, any interpretations on SAR in the npr3 npr4 double should take into consideration the hyper-resistant state of the npr3 npr4 double mutant plant. Fu et al. (2012) present a model in which NPR4 binds to and promotes NPR1 degradation in the presence of low SA levels to attenuate defense gene expression under basal conditions. The model also proposes that elevated SA following SAR establishment promotes the disruption of the NPR1-NPR4 complex but is not sufficient for promoting association of the low affinity SA receptor NPR3 with NPR1, thereby liberating NPR1 to activate defense gene expression.

In addition to NPR1, a genetic screen has identified NonRecognition-of-BTH4 (NRB4) as a mediator of SA responses in Arabidopsis (Canet et al., 2012). Plants carrying weak nrb4 alleles exhibit strong SA insensitivity and show, to a varying degree, attenuated SAR and compromised basal resistance to $P$. syringae. Like npr1, nrb4 mutants fail to develop SA- or BTHinduced resistance and over-accumulate SA in the course of $P$. syringae-infection. nrb4 null alleles also express severe growth defects, indicating a role of NRB4 in plant development. NRB4 is allelic to Mediator subunit 15 (MED15). Mediator represents a multiprotein complex that functions as a transcriptional coactivator or co-repressor in eukaryotes, depending on the nature of associated protein components. Individual Mediator subunits transduce diverse signals to the general transcriptional machinery and can thereby convey plant transcriptional responses to specific stimuli (Kidd et al., 2011). An Arabidopsis screen for reduced $P R 1$ activation upon exogenous $\mathrm{NAD}^{+}$application, a treatment that induces $P R$ gene expression and disease resistance in Arabidopsis (Zhang and Mou, 2009), identified Mediator subunit 16 (MED16) as an essential SAR component (Zhang et al., 2012). Med16 knockout lines exhibit increased susceptibility to Avr and virulent $P$. syringae and are unable to establish SAR. Following bacterial inoculation, med16 plants locally and systemically accumulate SA to similar levels than the wildtype but are impaired in $P R$ gene expression. Zhang et al. (2012) demonstrated that MED16 functions downstream of SA and positively regulates NPR1 protein accumulation. Beyond its function in the SA pathway, MED15 is also required for plant defense toward necrotrophic pathogens and activation of jasmonic acid (JA)/ethylene (ET) pathway genes. Thus, MED16 seems to relay signals from the SA pathway and the JA/ET pathway to the general transcription machinery. MED16 might regulate SA responsiveness via the modulation of NPR1 protein accumulation, but it is not clear yet whether NPR1 or TGA factors are physically associated with the Mediator subunit (Zhang et al., 2012).

\section{SAR - AN ALARMED STATE OF PLANTS THAT CONFERS DEFENSE PRIMING VIA PIP ACCUMULATION}

Several PR proteins exhibit antimicrobial activities in vitro and overexpression studies indicate that increased expression of single $P R$ genes can render plants more resistant to particular pathogen types (Sticher et al., 1997). This suggests that PR proteins that accumulate during SAR contribute to increased pathogen resistance by directly exerting harmful effects to microbial invaders. A second phenomenon supposed to confer resistance during SAR is defense priming or conditioning (Conrath, 2011). Defense priming can be interpreted as an alarmed or sensitized state of plants during which they are able to react more quickly and effectively to pathogen attack.

Although plant conditioning has been associated for a long time with biologically induced SAR (reviewed in Sticher et al., 1997), the phenomenon has been most convincingly described for experimental setups in which plants or plant cell cultures were exogenously treated with chemical enhancers of resistance. These compounds include plant-derived substances such as SA, thiamine and riboflavin (Thulke and Conrath, 1998; Ahn et al., 2007; Zhang et al., 2009), but often also synthetic or unnatural substances like BTH or $\beta$-amino butyric acid (BABA; Katz et al., 
1998; Zimmerli et al., 2000). Recently, a high-throughput chemical screen identified a series of novel synthetic compounds that confer defense priming by targeting SA glycosyltransferases and thus increasing endogenous SA accumulation (Noutoshi et al., 2012).

Recent studies indicate that a primary inoculation with a SAR-inducing pathogen leads to defense priming in distal leaves, enabling the whole plant to more effectively mobilize defenses in the course of a subsequent challenge infection (Jung et al., 2009; Návarová et al., 2012). Jung et al. (2009) demonstrated that biological SAR induction, similar to exogenous AzA treatment [see section "Azelaic Acid (AzA)"], enables plants to accumulate higher levels of SA and PR1 transcripts. This effect was not observed in plants disrupted for the AZI1 gene, which is transiently expressed at elevated levels in response to AzA treatment (Jung et al., 2009). However, genetic evidence that AzA is responsible for priming of SA production and responsiveness during biological SAR is lacking. Beckers et al. (2009) reported enhanced activation of mitogen-activated protein kinases (MPK) MPK3 and MPK6 upon mechanical stress (pressure infiltration of water) or P. syringae-exposure of leaves when Arabidopsis plants were previously treated with BTH. They found that full BTH-mediated priming of PAL1- and PR1- expression in response to mechanical stress was dependent on both MPK3 and MPK6. MPK3 but not MPK6 was also required for $P$. syringae-induced SAR. However, the role of the MPKs in priming of SAR-related defense responses to pathogen challenge following biological SAR induction was not investigated (Beckers et al., 2009). Another study established that BTH application and localized P. syringae-treatment systemically primed Arabidopsis for enhanced expression of the WRKY transcription factor genes WRK6, WRKY29, and WRKY53 in response to the stress associated with pressure-infiltration of water into leaves (Jaskiewicz et al., 2011). This priming of WRKY genes by BTH was dependent on NPR1. Concomitantly, BTH-treatment and $P$. syringae-inoculation also induced histone modifications in the chromatin at the promoters of these WRKY genes, suggesting that these histone modifications provide a form of memory of a previous stress. However, whether this histone modification-associated memory has a role in SAR-mediated priming and establishment of systemic immunity remains to be determined.

The recent study of Návarová et al. (2012) demonstrated that biologically-induced SAR in Arabidopsis plants promotes an alarmed state that accelerates the responses to subsequent pathogen attack on several levels. On the metabolite level, SAR priming is characterized by a strongly potentiated induction of both Pip biosynthesis and accumulation of the phytoalexin camalexin after $P$. syringae inoculation, and by a more moderate stimulation of SA accumulation. Moreover, biological SAR prepares plants for a stronger induction of defense genes after a challenge infection, including the two essential SAR regulatory genes ALD1 and FMO1, and the SA-inducible PR1. The Pip-deficient ald1 plants are defective in these SAR-associated conditioning events, suggesting that Pip accumulation is critical for SAR priming. This is corroborated by the findings that exogenous Pip promotes a sensitized state highly similar to that occurring after biological induction of SAR and compensates priming defects in ald1. Therefore, genetic and physiological evidence indicates that Pip accumulation is necessary and sufficient to promote a primed state after biological SAR induction (Návarová et al., 2012). Interestingly, the biosynthesis of the endogenous priming regulator Pip is also potentiated during biological SAR, indicating that feedback amplification mechanisms similar to those described in section "The Pip Resistance Pathway Is Central for SAR" for SAR establishment contribute to defense priming in the course of the challenge infection. Moreover, the observations that Pip also accumulates in BABA-treated plants to physiological levels, and that Pip-deficient ald 1 plants are defective in BABA-induced resistance to $P$. syringae suggest that BABA-induced resistance to hemibiotrophic bacteria is regulated via Pip-mediated priming events (Návarová et al., 2012).

\section{THE MEMORY OF SAR IS PASSED ON TO THE PROGENY}

SAR confers a fitness advantage under conditions of disease stress (Traw et al., 2007). A recent study indicated that the memory of SAR in Arabidopsis is passed on to the next generation, thus benefiting the progeny plants as well (Luna et al., 2012). The progeny of plants in which SAR had been activated by inoculation with a virulent strain of $P$. syringae pv tomato exhibited heightened resistance to $P$. syringae pv tomato as well as the unrelated oomycete $H$. parasitica than the progeny of plants that received a control mock-treatment. Although the basal content of defense hormones SA, JA, and JA-Ile were not altered in these next generation SAR plants, SAR associated defenses were more responsive to $S A$, as indicated by the more robust expression of $P R 1$ and the WRKY genes, WRKY6, WRKY53 and WRKY70 in these progeny when treated with SA, than in progeny of plants in which SAR was not induced (Luna et al., 2012). NPR1 was required for the next generation SAR. By contrast, the sensitivity of these next generation SAR progeny to JA was reduced, resulting in the weaker induction of JA-inducible genes (PDF1.2 and VSP2) in response to exogenously applied JA and a concomitant increase in susceptibility to the necrotrophic pathogen Botrytis cinerea. Similarly, enhanced protection in progeny plants has also been reported for plants treated with an Avr strain of P. syringae or BABA (Slaughter et al., 2012). Progeny of the BABA-treated plants were primed for SA-dependent resistance against $P$. syringae and $H$. arabidopsidis.

Luna et al. (2012) showed that next generation SAR was accompanied by changes in the methylation and acetylation status of histones at the promoters of various NPR1 regulated or SAR associated genes, including PR1, WRKY6, and WRKY53. Promoters of these genes in plants exhibiting next generation SAR contained elevated levels of histone 3 with acetylated Lys 9 (H3K9ac), which is considered a transcription activation mark. By contrast, the PDF1.2 promoter contained elevated levels of $\mathrm{H} 3 \mathrm{~K} 27 \mathrm{me} 3$, which is normally associated with transcriptional silencing. These results suggest that plants exhibiting next generation SAR have chromatin marks that likely are involved in retaining memory of an infection in the parental generation. In the absence of any evidence that histone modifications per se can be transmitted via the gametes, Luna et al. (2012) suggested that DNA methylation patterns, which can be transferred from one generation to another, are likely connected with transmission of memory associated with SAR from the parental generation to 
the progeny. Bacterial infection is known to cause hypomethylation (Pavet et al., 2006). Similarly, JA and SA treatment also have been reported to impact the DNA methylation status (Verhoeven et al., 2010). Luna et al. (2012) noted that basal resistance was higher in the $d r m 1 d r m 2 \mathrm{~cm}+3$ triple mutant in which non-CpG DNA methylations are reduced. In addition, the $d r m 1 d r m 2 \mathrm{cmt} 3$ plants also responded more robustly to SA thus mimicking the priming effect associated with next generation SAR. However, Slaughter et al. (2012) did not see any relationship between next generation protection conferred by BABA or bacterial inoculation and the methylation status at the PR1 promoter, thus suggesting that if DNA methylation changes are associated with transmission of the priming memory from the parent to the progeny, it is exerted not directly at the $P R 1$ promoter, but rather at the level of upstream regulatory genes. Next generation stress protection is not limited to defense against pathogens. It has also been reported in Arabidopsis and tomato (Solanum lycopersicum) subjected to mechanical damage or herbivory (Rasmann et al., 2012). In this case, the next generation protection was accompanied by priming of JA-dependent defenses. Epigenetic changes associated with next generation protection offer the advantage that they are not permanent and hence offer plasticity, which allows plants to better adapt to a changing environment.

\section{REFERENCES}

Ahn, I. P., Kim, S., Lee, Y. H., and Suh, S. C. (2007). Vitamin B1-induced priming is dependent on hydrogen peroxide and the NPR1 gene in Arabidopsis. Plant Physiol. 143, 838-848.

Attaran, E., Zeier, T. E., Griebel, T., and Zeier, J. (2009). Methyl salicylate production and jasmonate signaling are not essential for systemic acquired resistance in Arabidopsis. Plant Cell 21, 954-971.

Bartsch, M., Gobbato, E., Bednarek, P., Debey, S., Schultze, J. L., Bautor, J., et al. (2006). Salicylic acid-independent ENHANCED DISEASE SUSCEPTIBILITY1 signaling in Arabidopsis immunity and cell death is regulated by the monoxygenase FMOl and the nudix hydrolase NUDT7. Plant Cell 18, 1038-1051.

Beckers, G. J., Jaskiewicz, M., Liu, Y., Underwood, W. R., He, S. Y., Zhang, S., et al. (2009). Mitogen-activated protein kinases 3 and 6 are required for full priming of stress responses in Arabidopsis thaliana. Plant Cell 21, 944-953.

Bohlmann, J., and Keeling, C. I. (2008). Terpenoid biomaterials. Plant J. 54, 656-669.

Boyle, P., Le Su, E., Rochon, A., Shearer, H. L., Murmu, J., Chu, J. Y., et al. (2009). The BTB/POZ domain

of the Arabidopsis disease resis

\section{CONCLUDING REMARKS}

Although SAR confers a fitness advantage that can benefit multiple generations of plants (Traw et al., 2007; Luna et al., 2012), it needs to be tightly regulated since it is an energy-driven process that diverts resources from growth and development (Heidel et al., 2004; Pajerowska-Mukhtar et al., 2012). Hence, uncontrolled and untimely activation of SAR is detrimental for plant growth and development. Pathogens are also known to target plant defenses to facilitate infection. A circuitry involving networking between multiple signals (Figure 3) offers plants the advantage of having sufficient flexibility to better control SAR under different environmental conditions. The coming years will be important for understanding the molecular components of this circuitry, its regulation, conservation amongst plants and the application of this knowledge to sustainable agriculture.

\section{ACKNOWLEDGMENTS}

This work was supported by grants to Jyoti Shah from the National Science Foundation (IOS-1121570 and MCB-0920600) and the U.S. Department of Agriculture as a cooperative project with the U.S. Wheat \& Barley Scab Initiative (Agreement No. 590790-8-060), and to Jürgen Zeier from the Swiss National Science Foundation (SNF grant No. 3100A-125374) and the German Research Foundation (DFG Graduate program IRTG 1525).

immunity in plants. Nat. Genet. 43, 421-427. tance protein NPR1 interacts with the repression domain of TGA2 to negate its function. Plant Cell 21, 3700-3713.

Broquist, H. P. (1991). Lysine-pipecolic acid metabolic relationships in microbes and mammals. Annu. Rev. Nutr. 11, 435-448.

Canet, J. V., Dobón, A., and Tornero, P. (2012). Non-recognition-ofBTH4, an Arabidopsis mediator subunit homolog, is necessary for development and response to salicylic acid. Plant Cell 24, 4220-4235.

Catinot, J., Buchala, A., AbouMansour, E., and Métraux, J. P. (2008). Salicylic acid production in response to biotic and abiotic stress depends on isochorismate in Nicotiana benthamiana. FEBS Lett. 582, 473-478.

Champigny, M. J., Shearer, H., Mohammad, A., Haines, K., Neumann, M., Thilmony, R., et al. (2011). Localization of DIR1 at the tissue, cellular and subcellular levels during Systemic Acquired Resistance in Arabidopsis using DIR1:GUS and DIR1:EGFP reporters. BMC Plant Biol. 11:125. doi: 10.1186/1471-2229-11-125

Chanda, B., Xia, Y., Mandal, M. K., Yu, K., Sekine, K.-T., Gao, Q.-M., et al. (2011). Glycerol-3-phosphate is a critical mobile inducer of systemic
Chang, Y.-F. (1976). Pipecolic acid pathway: the major lysine metabolic route in the rat brain. Biochem. Biophys. Res. Commun. 69, 174-180.

Chaturvedi, R., Krothapalli, K., Makandar, R., Nandi, A., Sparks, A., Roth, M. R., et al. (2008). Plastid $\omega$-3 desaturase-dependent accumulation of a systemic acquired resistance inducing activity in petiole exudates of Arabidopsis thaliana is independent of jasmonic acid. Plant J. 54, 106-117.

Chaturvedi, R., and Shah, J. (2007). "Salicylic acid in plant disease resistance," in Salicylic Acid A Plant Hormone, eds S. Hayat and A. Ahmad (Dordrecht, The Netherlands: Springer), 335-370.

Chaturvedi, R., Venables, B., Petros, R. A., Nalam, V., Li, M., Wang, X., et al. (2012). An abietane diterpenoid is a potent activator of systemic acquired resistance. Plant J. 71, 161-172.

Chester, K. S. (1933). The problem of acquired physiological immunity in plants. Q. Rev. Biol. 8, 275-324.

Conrath, U. (2011). Molecular aspects of defence priming. Trends Plant Sci. 16, 524-531.

Dempsey, D. A., and Klessig, D. F. (2012). SOS - too many signals for systemic acquired resistance? Trends Plant Sci. 17, 538-545.
Despres, C., DeLong, C., Glaze, S. Liu, E., and Fobert, P. R. (2000). The Arabidopsis NPR1/NIM1 protein enhances the DNA binding activity of a subgroup of the TGA family of bZIP transcription factors. Plant Cell 12, 279-290.

Durrant, W. E., and Dong, X. (2004). Systemic acquired resistance. Annu. Rev. Phytopathol. 42, 185-209.

Forouhar, F., Yang, Y., Kumar, D., Chen, Y., Fridman, E., Park, S. W., et al. (2005). Structural and biochemical studies identify tobacco SABP2 as a methyl salicylate esterase and implicate it in plant innate immunity. Proc. Natl. Acad. Sci. U.S.A. 102, 1773-1778.

Fu, Z. Q., Yan, S., Saleh, A., Wang, W., Ruble, J., Oka, N., et al. (2012). NPR3 and NPR4 are receptors for the immune signal salicylic acid in plants. Nature 486, 228-232.

Fujioka, S., Sakurai, A., Yamaguchi, I., Murofushi, N., Takahashi, N., Kaihara, S., et al. (1987). Isolation and identification of L-pipecolic acid and nicotinamide as flowerinducing substances in Lemna. Plant Cell Physiol. 28, 995-1003.

Gessler, C., and Kuc, J. (1982). Induction of resistance to Fusarium wilt in cucumber by root and foliar pathogens. Phytopathology 72, 1439-1441.

Griebel, T., and Zeier, J. (2008). Light regulation and daytime dependency 
of inducible plant defenses in Arabidopsis: phytochrome signaling controls systemic acquired resistance rather than local defense. Plant Physiol. 147, 790-801.

Griebel, T., and Zeier, J. (2010). A role for $\beta$-sitosterol to stigmasterol conversion in plant-pathogen interactions. Plant J. 63, 254-268.

Guedes, M. E. M., Richmond, S., and Kuc, J. (1980). Induced systemic resistance to anthracnose in cucumber as influenced by the location of the inducer inoculation with Colletotrichum lagenarium and the onset of flowering and fruiting. Physiol. Plant Pathol. 17, 229-233.

Hanson, J. R. (2009). Diterpenoids. Nat. Prod. Rep. 26, 1156-1171.

Heidel, A. J., Clarke, J. D., Antonovics, J., and Dong, X. (2004). Fitness costs of mutations affecting the systemic acquired resistance pathway in Arabidopsis thaliana. Genetics 168, 2197-2206.

Jaskiewicz, M., Conrath, U., and Peterhänsel, C. (2011). Chromatin modification acts as a memory for systemic acquired resistance in the plant stress response. EMBO Rep. $12,50-55$.

Jenns, A., and Kuc, J. (1979). Graft transmission of systemic resistance of cucumber to anthracnose induced by Colletotrichum lagenarium and tobacco necrosis virus. Phytopathology 69, 753-756.

Jing, B., Xu, S., Xu, M., Li, Y., Li, S., Ding, J., et al. (2011). Brush and spray: a high-throughput systemic acquired resistance assay suitable for large-scale genetic screening. Plant Physiol. 157, 973-980.

Jirage, D., Tootle, T. L., Reuber, T. L., Frost, L. N., Feys, B. J., Parker, J. E., et al. (1999). Arabidopsis thaliana PAD4 encodes a lipase-like gene that is important for salicylic acid signaling. Proc. Natl. Acad. Sci. U.S.A. 96, 13583-13588.

Jones, J. D. G., and Dangl, J. L. (2006). The plant immune system. Nature 444, 323-329.

Jung, H. W., Tschaplinski, T. J., Wang, L., Glazebrook, J., and Greenberg, J. T. (2009). Priming in systemic plant immunity. Science 324, 89-91.

Katz, V. A., Thulke, O. U., and Conrath, U. (1998). A benzothiadiazole primes parsley cells for augmented elicitation of defense responses. Plant Physiol. 117, 1333-1339.

Kesarwani, M., Yoo, J., and Dong, X. (2007). Genetic interactions of TGA transcription factors in the regulation of pathogenesis-related genes and disease resistance in Arabidopsis. Plant Physiol. 144, 336-346.
Kidd, B. N., Cahill, D. M., Manners, J. M., Schenk, P. M., and Kazan, K. (2011). Diverse roles of the Mediator complex in plants. Semin. Cell Dev. Biol. 22, 741-748.

Kiefer, I. W., and Slusarenko, A. J. (2003). The pattern of systemic acquired resistance induction within the Arabidopsis rosette in relation to the pattern of translocation. Plant Physiol. 132, 840-847.

Kinkema, M., Fan, W., and Dong, X. (2000). Nuclear localization of NPR1 is required for activation of $P R$ gene expression. Plant Cell 12, 2339-2350.

Koch, M., Vorwerk, S., Masur, C., Sharifi-Sirchi, G., Olivieri, N., and Schlaich, N. L. (2006). A role for a flavin-containing monooxygenase in resistance against microbial pathogens in Arabidopsis. Plant J. 47, 629-639.

Kumar, D., Gustafsson, C., and Klessig, D. F. (2006). Validation of RNAi silencing specificity using synthetic genes: salicylic acid-binding protein 2 is required for innate immunity in plants. Plant J. 45, 863-868.

Lascombe, M.-B., Bakan, B., Buhot, N., Marion, D., Blein, J.-P., Larue, V., et al. (2008). The structure of "defective in induced resistance" protein of Arabidopsis thaliana, DIR1, reveals a new type of lipid transfer protein. Protein Sci. 17, 1522-1530.

Lawton, K., Weymann, K., Friedrich, L., Vernooij, B., Uknes, S., and Ryals, J. (1995). Systemic acquired resistance in Arabidopsis requires salicylic acid but not ethylene. Mol. Plant-Microbe Interact. 8, 863-870.

Li, B., Gao, R., Cui, R., Lu, B., Li, X., Zhao, Y., et al. (2012). Tobacco TTG2 suppresses resistance to pathogens by sequestering NPR1 from the nucleus. J. Cell Sci. 125, 4913-4922.

Li, J., Hansen, B. G., Ober, J. A., Kliebenstein, D. J., and Halkier, B. A. (2008). Subclade of flavinmonooxygenases involved in aliphatic glucosinolate biosynthesis. Plant Physiol. 148, 1721-1733.

Liu, J., Maldonado-Mendoza, I., LopezMeyer, M., Cheung, F., Town, C. D., and Harrison, M. J. (2007). Arbuscular mycorrhizal symbiosis is accompanied by local and systemic alterations in gene expression and an increase in disease resistance in the shoots. Plant J. 50, 529-544.

Liu, P. P., von Dahl, C. C., and Klessig, D. F. (2011a). The extent to which methyl salicylate is required for signaling systemic acquired resistance is dependent on exposure to light after infection. Plant Physiol 157, 2216-2226.

Liu, P. P., von Dahl, C. C., Park, S. W., and Klessig, D. F. (2011b) Interconnection between methyl salicylate and lipid-based long distance signaling during the development of systemic acquired resistance in Arabidopsis and tobacco. Plant Physiol. 144, 1762-1768.

Liu, P.-P., Yang, Y., Pichersky, E., and Klessig, D. F. (2010). Altering expression of Benzoic acid/salicylic acid carboxyl methyltransferase 1 compromises systemic acquired resistance and PAMP-triggered immunity in Arabidopsis. Mol. Plant-Microbe Interact. 23, 82-90.

Lorenc-Kukula, K., Chaturvedi, R., Roth, M., Welti, R., and Shah, J. (2012). Biochemical and molecular-genetic characterization of SFD1's involvement in lipid metabolism and defense signaling. Front. Plant Sci. 3:26. doi: 10.3389/fpls.2012.00026

Luna, E., Bruce, T. J. A., Roberts, M. R., Flors, V., and Ton, J. (2012). Next generation systemic acquired resistance. Plant Physiol. 158, 844-853.

Maier, F., Zwicker, S., Hückelhoven, A. Meissner, M., Funk, J., Pfitzner, A. J., et al. (2011). NONEXPRESSOR OF PATHOGENESIS-RELATED PROTEINS1 (NPR1) and some NPR1-related proteins are sensitive to salicylic acid. Mol. Plant Pathol. 12, 73-91.

Malamy, J., Carr, J. P., Klessig, D. F., and Raskin, I. (1990). Salicylic acid: a likely endogenous signal in the resistance response of tobacco to viral infection. Science 250, 1002-1004.

Maldonado, A. M., Doerner, P., Dixon, R. A., Lamb, C. J., and Cameron, R. K. (2002). A putative lipid transfer protein involved in systemic acquired resistance signalling in Arabidopsis. Nature 419, 399-403.

Manosalva, P. M., Park, S. W., Forouhar, F., Tong, L., Fry, W. E., and Klessig, D. F. (2010). Methyl Esterase 1 (StMES1) is required for systemic acquired resistance in potato. Mol. Plant-Microbe Interact. 23, 1151-1163.

Métraux, J. P., Signer, H., Ryals, J., Ward, E., Wyss-Benz, M., Gaudin, J., et al. (1990). Increase in salicylic acid at the onset of systemic acquired resistance in cucumber. Science 250, 1004-1006.

Mishina, T. E., and Zeier, J. (2006). The Arabidopsis flavin-dependent monooxygenase FMO1 is an essential component of biologically induced systemic acquired resistance. Plant Physiol. 141, 1666-1675.

Mishina, T. E., and Zeier, J. (2007). Pathogen-associated molecular pattern recognition rather than development of tissue necrosis contributes to bacterial induction of systemic acquired resistance in Arabidopsis. Plant J. 50, 500-513.

Mishina, T. E., Griebel, T., Geuecke, M., Attaran, E., and Zeier, J. (2008). "New insights into the molecular events underlying systemic acquired resistance," in Biology of PlantMicrobe Interactions, Vol. 6, eds M. Lorito, S. L. Woo, and F. Scala (St. Paul, MN: International Society for Molecular Plant-Microbe Interactions), 81.

Morrison, R. I. (1953). The isolation of L-pipecolinic acid from Trifolium repens. Biochem. J. 53, 474-478.

Mou, Z., Fan, W., and Dong, X. (2003). Inducers of plant systemic acquired resistance regulate NPR1 function through redox changes. Cell 113, 935-944.

Moulin, M., Deleu, C., Larher, F., and Bouchereau, A. (2006). The lysine-ketoglutarate reductasesaccharopine dehydrogenase is involved in the osmo-induced synthesis of pipecolic acid in rapeseed leaf tissues. Plant Physiol. Biochem. 44, 474-482.

Nandi, A., Krothapalli, K., Buseman, C., Li, M., Welti, R., Enyedi, A., et al. (2003). The Arabidopsis thaliana sfd mutants affect plastidic lipid composition and suppress dwarfing, cell death and the enhanced disease resistance phenotypes resulting from the deficiency of a fatty acid desaturase. Plant Cell 15, 2383-2398.

Nandi, A., Welti, R., and Shah, J. (2004). The Arabidopsis thaliana dihydroxyacetone phosphate reductase gene SUPPRESSOR OF FATTY ACID DESATURASE DEFICIENCY1 is required for glycerolipid metabolism and for the activation of systemic acquired resistance. Plant Cell 16, 465-477.

Návarová, H., Bernsdorff, F., Döring, A.-C., and Zeier, J. (2012). Pipecolic acid, an endogenous mediator of defense amplification and priming, is a critical regulator of inducible plant immunity. Plant Cell 24, 5123-5141.

Nawrath, C., and Métraux, J.-P. (1999). Salicylic acid induction-deficient mutants of Arabidopsis express PR-2 and PR-5 and accumulate high levels of camalexin after pathogen inoculation. Plant Cell 11, 1393-1404. 
Noutoshi, Y., Okazaki, M., Kida, T., Nishina, Y., Morishita, Y., Ogawa, T., et al. (2012). Novel plant immunepriming compounds identified via high-throughput chemical screening target salicylic acid glucosyltransferases in Arabidopsis. Plant Cell 24, 3795-3804.

Olszak, B., Malinovsky, F. G., Brodersen, P., Grell, M., Giese, H., Petersen, M., et al. (2006). A putative flavin-containing monooxygenase as a marker for certain defense and cell death pathways. Plant Sci. 170, 614-623.

Pajerowska-Mukhtar, K. M., Wang, W., Tada, Y., Oka, N., Tucker, C. L., Fonesca, J. P., et al. (2012). The HSFlike transcription factor TBF1 is a major molecular switch for plant growth-to-defense transition. Curr. Biol. 22, 103-112.

Pálfi, G., and Dézsi, L. (1968). Pipecolic acid as an indicator of abnormal protein metabolism in diseased plants. Plant Soil 29, 285-291.

Pallas, J. A., Paiva, N. L., Lamb, C., and Dixon, R. A. (1996). Tobacco plants epigenetically suppressed in phenylalanine ammonia-lyase expression do not develop systemic acquired resistance in response to infection by tobacco mosaic virus. Plant J. 10, 281-293.

Park, S.-W., Kaimoyo, E., Kumar, D., Mosher, S., and Klessig, D. F. (2007). Methyl salicylate is a critical mobile signal for plant systemic acquired resistance. Science 318, 113-116.

Park, S.-W., Liu, P.-P., Forouhar, F., Vlot, A. C., Tong, L., Tietjen, K., et al. (2009). Use of a synthetic salicylic acid analog to investigate the roles of methyl salicylate and its esterases in plant disease resistance. J. Biol. Chem. 284, 7307-7317.

Pavet, V., Quintero, C., Cecchini, N. M., Rosa, A. L., and Alvarez, M. E. (2006). Arabidopsis displays centromeric DNA hypomethylation and cytological alterations of heterochromatin upon attack by Pseudomonas syringae. Mol. Plant-Microbe Interact. 19, 577-587.

Rasmann, S., De Vos, M., Casteel, C. L., Tian, D., Halitschke, R., Sun, J. Y., et al. (2012). Herbivory in the previous generation primes plants for enhanced insect resistance. Plant Physiol. 158, 854-863.

Rochon, A., Boyle, P., Wignes, T., Fobert, P. R., and Després, C. (2006). The coactivator function of Arabidopsis NPR1 requires the core of its BTB/POZ domain and the oxidation of C-terminal cysteines. Plant Cell 18, 3670-3685.
Ross, A. F. (1966). "Systemic effects of local lesion formation," in Viruses of Plants, eds A. B. R. Beemster and J. Dijkstra (Amsterdam: NorthHolland Publishing), 127-150.

Schlaich, N. L. (2007). Flavincontaining monooxygenases in plants: looking beyond detox. Trends Plant Sci. 12, 412-418.

Shah, J. (2009). Plants under attack: systemic signals in defence. Curr. Opin. Plant Biol. 12, 459-464.

Shah, J., Kachroo, P. K., Nandi, A., and Klessig, D. F. (2001). A recessive mutation in the Arabidopsis SSI2 gene confers SA- and NPR1independent expression of $P R$ genes and resistance against bacterial and oomycete pathogens. Plant J. 25, 563-574.

Shoresh, M., Harman, G. E., and Mastouri, F. (2010). Induced systemic resistance and plant responses to fungal biocontrol agents. Annu. Rev. Phytopathol. 48, 21-43.

Shulaev, V., Silverman, P., and Raskin, I. (1997). Airborne signalling by methyl salicylate in plant pathogen resistance. Nature 385, 718-721.

Slaughter, A., Daniel, X., Flors, V., Luna, E., Hohn, B., and MauchMani, B. (2012). Descendants of primed Arabidopsis plants exhibit resistance to biotic stress. Plant Physiol. 158, 835-843.

Snoeren, T. A. L., Mumm, R., Poelman, E. H., Yang, Y., Pichersky, E., and Dicke, M. (2010). The herbivoreinduced plant volatile methyl salicylate negatively affects attraction of the parasitoid Diadegma semiclausum. J. Chem. Ecol. 36, 479-489.

Song, J., Lu, H., and Greenberg, J. (2004a). Divergent roles in Arabidopsis thaliana development and defense of two homologous genes, ABERRANT GROWTH AND DEATH2 and AGD2-LIKE DEFENSE RESPONSE PROTEIN1, encoding novel aminotransferases. Plant Cell 16, 353-366.

Song, J., Lu, H., McDowell, J. M., and Greenberg, J. (2004b). A key role for $A L D 1$ in activation of local and systemic defenses in Arabidopsis. Plant J. 40, 200-212.

Spoel, S. H., and Dong, X. (2012). How do plants achieve immunity? Defence without specialized immune cells. Nat. Rev. Immunol. 12, 89-100.

Spoel, S. H., Mou, Z., Tada, Y., Spivey, N. W., Genschik, P., and Dong, X. (2009). Proteasome-mediated turnover of the transcription coactivator NPR1 plays dual role in regulating plant immunity. Cell 317 , 860-872.
Sticher, L., Mauch-Mani, B., and Métraux, J. P. (1997). Systemic acquired resistance. Annu. Rev. Phytopathol. 35, 235-270.

Tahiri-Alaoui, A., Dumas-Gaudot, E., Gianinazzi, S., and Antoniw, J. F. (1993). Expression of the PR-b1 gene in roots of two Nicotiana species and their amphidiploid hybrid infected with virulent and avirulent races of Chalara elegans. Plant. Pathol. 42, 728-736.

Tholl, D. (2006). Terpene synthases and the regulation, diversity and biological roles of terpene metabolism. Curr. Opin. Plant Biol. 9, 297-304.

Thulke, O., and Conrath, U. (1998). Salicylic acid has a dual role in the activation of defence-related genes in parsley. Plant J. 14, 35-42.

Trapp, S., and Croteau, R. (2001). Defensive resin biosynthesis in conifers. Annu. Rev. Plant Physiol. Plant. Mol. Biol. 52, 689-724.

Traw, M. B., Kniskern, J. M., and Bergelson, J. (2007). SAR increases fitness of Arabidopsis thaliana in the presence of natural bacterial pathogens. Evolution 61, 2444-2449.

Tuzun, S., and Kuc, J. (1985). Movement of a factor in tobacco infected with Peranospora tabacina Adam which systemically protects against blue mold. Physiol. Plant. Pathol. 26, 321-330.

van Loon, L. C. (2007). Plant responses to plant growth-promoting rhizobacteria. Eur. J. Plant Pathol. 119, 243-354.

Van Poecke, R. M. P., and Dicke, M. (2002). Induced parasitoid attraction by Arabidopsis thaliana: involvement of the octadecanoid and the salicylic acid pathway. J. Exp. Bot. 53, 1793-1799.

van Wees, S. C. M., de Swart, E. A. M., van Pelt, J. A., van Loon, L. C., and Pieterse, C. M. J. (2000). Enhancement of induced disease resistance by simultaneous activation of salicylate- and jasmonate-dependent defense pathways in Arabidopsis thaliana. Proc. Natl. Acad. Sci. U.S.A. 97, 8711-8716.

Verhoeven, K. J. F., Jansen, J. J., van Dijk, P. J., and Biere, A. (2010). Stress-induced DNA methylation changes and their heritability in asexual dandelions. New Phytol. 185, 1108-1118.

Vernooij, B., Friedrich, L., Morse, A., Reist, R., Kolditz-Jawhar, R., Ward, E., et al. (1994). Salicylic acid is not the translocated signal responsible for inducing systemic acquired resistance. Plant Cell 6, 959-965.
Vicente, J., Cascón, T., Vicedo, B., Garcia-Agustin, P., Hamberg, M., and Castresana, C. (2012). Role of 9-Lipoxygenase and $\alpha$-dioxygenase oxylipin pathways as modulators of local and systemic defense. Mol. Plant. 5, 914-928.

Vlot, A. C., Liu, P.-P., Cameron, R. K., Park, S.-W., Yang, Y., Kumar, D., et al. (2008). Identification of likely orthologs of tobacco salicylic acid-binding protein 2 and their role in systemic acquired resistance in Arabidopsis thaliana. Plant J. 56, 445-456.

Wang, D., Weaver, N. D., Kesarwani, M., and Dong, X. (2005). Induction of protein secretory pathway is required for systemic acquired resistance. Science 308 1036-1040.

Wang, L., Tsuda, K., Truman, W., Sato, M., Nguyen, L. V., Katagiri, F., et al. (2011). CBP60g and SARD1 play partially redundant critical roles in salicylic acid signaling. Plant J. 67, 1029-1041.

Ward, J. L., Forcat, S., Beckmann, M., Bennett, M., Miller, S. J., Baker, J. M., et al. (2010). The metabolic transition during disease following infection of Arabidopsis thaliana by Pseudomonas syringae pv. tomato. Plant J. 63, 443-457.

Wildermuth, M. C., Dewdney, J., Wu, G., and Ausubel, F. M. (2001). Isochorismate synthase is required to synthesize salicylic acid for plant defence. Nature 414, 562-565.

Wu, Y., Zhang, D., Chu, J. Y., Boyle, P., Wang, Y., Brindle, I. D., et al. (2012). The Arabidopsis NPR1 protein is a receptor for the plant defense hormone salicylic acid. Cell Reports 1, 639-647.

Yatsu, L., and Boynton, D. (1959). Pipecolic acid in leaves of strawberry plant as influenced by treatments affecting growth. Science 130, 864-865.

Zeier, J., Pink, B., Mueller, M. J., and Berger, S. (2004). Light conditions influence specific defence responses in incompatible plantpathogen interactions uncoupling systemic resistance from salicylic acid and PR-1 accumulation. Planta 219, 673-683.

Zhang, S., Yang, X., Sun, M., Sun, F., Deng, S., and Dong, H. (2009). Riboflavin-induced priming for pathogen defense in Arabidopsis thaliana. J. Integr. Plant Biol. 51, 167-174.

Zhang, X., and Mou, Z. (2009). Extracellular pyridine nucleotides induce $P R$ gene expression and disease resistance in Arabidopsis. Plant J. 57, 302-312. 
Zhang, X., Wang, C., Zhang, Y., Sun, Y., and Mou, Z. (2012). The Arabidopsis mediator complex subunit16 positively regulates salicylate-mediated systemic acquired resistance and jasmonate/ethylene-induced defense pathways. Plant Cell 24, 4294-4309.

Zhang, Y., Tessaro, M. J., Lassner, M., and Li, X. (2003). Knockout analysis of Arabidopsis transcription factors TGA2, TGA5, and TGA6 reveals their redundant and essential roles in systemic acquired resistance. Plant Cell 15, 2647-2653.

Zhang, Y., Xu, S., Ding, P., Wang, D., Cheng, Y. T., He, J., et al. (2010). Control of salicylic acid synthesis and systemic acquired resistance by two members of a plant-specific family of transcription factors. Proc. Natl Acad. Sci. U.S.A. 107, 18220-18225.

Zhao, Y., Christensen, S. K., Fankhauser, C., Cashman, J. R., Cohen, J. D., Weigel, D., et al. (2001). A role for flavin monooxygenase-like enzymes in auxin biosynthesis. Science 291, 306-309.

Zhou, N., Tootle, T. L., Tsui, F., Klessig, D. F., and Glazebrook, J. (1998). PAD4 functions upstream from salicylic acid to control defence responses in Arabidopsis. Plant Cell 10, 1021-1030.

Zimmerli, L., Jakab, G., Métraux, J.P., and Mauch-Mani, B. (2000). Potentiation of pathogen-specific defense mechanisms in Arabidopsis by $\beta$-aminobutyric acid. Proc. Natl. Acad. Sci. U.S.A. 97, 12920-12925.

Zoeller, M., Stingl, N., Krischke, M., Fekete, A., Waller, F., Berger, S., et al. (2012). Lipid profiling of the Arabidopsis hypersensitive response reveals specific lipid peroxidation and fragmentation processes: biogenesis of pimelic and azelaic acid. Plant Physiol. 160, 365-378.

Conflict of Interest Statement: The authors declare that the research was conducted in the absence of any commercial or financial relationships that could be construed as a potential conflict of interest.

Received: 20 December 2012; paper pending published: 28 January 2013; accepted: 06 February 2013; published online: 22 February 2013.

Citation: Shah J and Zeier J (2013)

Long-distance communication and signal amplification in systemic acquired resistance. Front. Plant Sci. 4:30. doi: 10.3389/fpls.2013.00030

This article was submitted to Frontiers in Plant-Microbe Interaction, a specialty of Frontiers in Plant Science.

Copyright (c) 2013 Shah and Zeier. This is an open-access article distributed under the terms of the Creative Commons Attribution License, which permits use, distribution and reproduction in other forums, provided the original authors and source are credited and subject to any copyright notices concerning any third-party graphics etc. 